\title{
Crystallization of Calcium Carbonate and Magnesium Hydroxide in the Heat Exchangers of Once-through Multistage Flash (MSF-OT) Desalination Process
}

\author{
Salih Alsadaie ${ }^{\mathrm{a}}$ and Iqbal M. Mujtaba ${ }^{\mathrm{b}^{*}}$ \\ ${ }^{a}$ Chemical Engineering Department, Faculty of Engineering, University of Sirte, Sirte, Libya \\ ${ }^{\mathrm{b}}$ School of Engineering, University of Bradford, Bradford BD7 1DP, UK \\ *..M.Mujtaba@bradford.ac.uk
}

\begin{abstract}
In this paper, a dynamic model of fouling is presented to predict the crystallization of calcium carbonate and magnesium hydroxide inside the condenser tubes of Once-Through Multistage Flash (MSF-OT) desalination process. The model considers the combination of kinetic and mass diffusion rates taking into account the effect of temperature, velocity and salinity of the seawater. The equations for seawater carbonate system are used to calculate the concentration of the seawater species. The effects of salinity and temperature on the solubility of calcium carbonate and magnesium hydroxide are also considered. The results reveal an increase in the fouling inside the tubes caused by crystallization of $\mathrm{CaCO}_{3}$ and $\mathrm{Mg}(\mathrm{OH})_{2}$ with increase in the stage temperature. The intake seawater temperature and the Top Brine Temperature (TBT) are varied to investigate their impact on the fouling process. The results show that the (TBT) has greater impact than the seawater temperature on increasing the fouling.
\end{abstract}

Keywords: MSF Desalination, heat exchanger, fouling model, calcium carbonate, magnesium hydroxide, solubility product.

\section{Introduction}

Once-through multistage flash (MSF-OT) process is an earlier version of thermal seawater desalination process that is known for its simplicity and low capital investment compared with the conventional multistage flash desalination with recycle brine (MSF-BR). Since the seawater used in MSF-OT process is less saline than that used in the MSF-BR process, it consumes less thermal energy because of the lower Boiling Point Elevation (BPE) [1]. However, due to the missing of the recycle brine stream, MSF-OT process consume a large amount of intake seawater that has to be treated with antiscalant to overcome the tendency of the scale of formation resulting in a high amount of consumed chemical additives which increases the operating costs. As a result, most of the desalination plants were replaced by MSF-BR process. However, the situation has changed in recent years resulting in cheap and very effective antiscalant, hence, there is no justification to favour MSF-BR process on the account of the chemical expenses [2]. In addition, understanding the fouling phenomenon can reduce large amount of the antiscalant used.

Fouling is the accumulation of undesired solid materials at the heat transfer surface. The continuous build-up of the fouling film leads to an increase in the thermal resistance and deteriorates the performance of the plant. In thermal desalination process such as MSF, the phenomenon of fouling is mainly caused by crystallization of alkaline such as calcium 
carbonate $\left(\mathrm{CaCO}_{3}\right)$, and at higher temperature, magnesium hydroxide $\left(\mathrm{Mg}(\mathrm{OH})_{2}\right)$. The $\left(\mathrm{HCO}_{3}{ }^{-}\right)$normally break down to form $\mathrm{CO}_{3}{ }^{2-}$ at temperature above $45{ }^{\circ} \mathrm{C}$ causing the crystallization of $\mathrm{CaCO}_{3}$ once its solubility limit is exceeded. Shams El Din and Mohammed [3] conducted experimental study and found that the $\mathrm{CaCO}_{3}$ starts to form above $65{ }^{\circ} \mathrm{C}$ and reaches its maximum value at $80{ }^{\circ} \mathrm{C}$ while $\mathrm{Mg}(\mathrm{OH})_{2}$ starts crystallizing around $75{ }^{\circ} \mathrm{C}$ and increases steadily with temperature. The fouling, in general, is an extremely complex process that may be explained by mass, heat transfer and chemical reaction equations with respect to the properties of the scale material and the water. At heated surfaces, the fouling process undergoes five stages as follows [4]:

$\checkmark$ Initiation: slow nucleation of the fouling species at the surface to prepare the heated surface for more unsteady state growth of scale formation.

$\checkmark$ Transport: it is the transport of the fouling species to the surface by diffusion process due to concentration difference between the bulk phase and the liquid-solid surface. Particle size and the velocity of the bulk play an important role in accelerating or decelerating the transport process.

$\checkmark$ Attachment: it is the accumulation of the fouling species on the surface. Density, elasticity and the roughness of the surface material play an important role in sticking these species on the surface and thus, not all the transported species have to be deposited.

$\checkmark$ Removal: the disengagement of the fouling species from the surface into the bulk phase due to higher velocity, shear force and the roughness of the surface, and,

$\checkmark$ Aging: after a period of time, the strength of the deposited scale can vary with time resulting in break off of the scale into parts.

Although a good amount of studies were carried out on the experimental study of fouling only a handful of such studies focused on the modelling (or attempts to modelling) of fouling in MSF process [5-7]. Most of these models except [6, 8-11] have been developed and studied on their own but have not been a part of the MSF process models. Al-Rawajfeh, et al. [8] studied the deposition of calcium carbonate in flash chambers in MSF-OT and MSF-BR processes by correlating the deposition of calcium carbonate to the released rate of carbon dioxide in a steady state model based on coupling of mass transfer with chemical reaction. Al-Rawajfeh, et al. [9] extended the work of Al-Rawajfeh, et al. [8] to include deposition of calcium sulphate with calcium carbonate inside the tubes and flash chambers in MSF-OT and MSF-BR processes. However, though the authors pointed out the possible effect that the removal rate could have, their study only considered the rate of deposition but neglected the removal rate. Hawaidi and Mujtaba [6] developed a linear dynamic model for brine heater fouling to study the impact of fouling with seasonal variation of seawater temperatures using MSF-BR process. The model was lumped and no real focus on the chemistry of water was paid. Said, et al. [11] extended Hawaidi and Mujtaba's study to include the effect of fouling in the stages by development of steady state model of MSF-BR process. Again, the fouling was considered as lumped parameter and no details on the $\mathrm{CaCO}_{3}$ or $\mathrm{Mg}(\mathrm{OH})_{2}$ was presented. However, all the above studies considered the effect of one parameter (temperature) only. The 
effect of the variation of velocity due to the decrease in the cross section area of the tubes and also the effect of salinity were neglected. Moreover, note that during the accumulation of fouling, the MSF process experiences a continuous change in the tubes surface temperature. Alsadaie and Mujtaba [10] presented very detailed fouling model that considered the attached and removal rate of calcium carbonate and magnesium hydroxide and also it considered the effect of temperature, velocity and salinity. Though the model considered a combination of kinetic and mass diffusion of calcium carbonate, it neglected the diffusion rate of magnesium hydroxide. Moreover, the model was applied on MSF-BR process and no comparison on MSF-OT was made.

The MSF-OT process operates at low salinity and thus the tendency of fouling is expected to be lower in MSF-OT process than in MSF-BR process inside the condenser tubes and brine heater. Moreover, with the availability and at lower cost of corrosion resistant materials and antiscalant, the world of water desalination is expected to move back to MSF-OT technique for future plants for its simplicity and less energy consumption. Thus, it becomes very essential to study the crystallization behaviour of calcium carbonate and magnesium hydroxide inside the condenser tubes of MSF-OT process.

Therefore, in this work, a dynamic fouling model considering the crystallization of calcium carbonate and magnesium hydroxide is developed to investigate the behaviour of fouling in MSF-OT process with a continuous change in velocities and temperature due to the accumulation of fouling. The mass diffusion of magnesium hydroxide has been neglected in all previous developed models and thus, the proposed model here considers the combination of kinetic and mass diffusion of both calcium carbonate and magnesium hydroxide. The effect of seawater flowrate, seawater, temperature, seawater salinity and top brine temperature was investigated.

\section{Process Description}

The MSF-OT process, as illustrated in Figure 1, is an applied desalination method particularly known for its simplicity and a small number of components. The intake seawater at the cold inlet temperature is pumped into the inside of condenser tubes of the last flashing stage in right side (stage 21). The seawater gradually gets heated as it passes through the condenser tubes (heat exchangers) from one stage to another by exchanging the thermal energy from the flashing vapour in each stage. Passing through the first stage, the preheated brine (first stage outlet seawater) enters the brine heater, where its temperature is further raised to the desired temperature (TBT). At this point, the flashing brine enters the flash chamber of the first stage through an orifice or weir, where the pressure is reduced in such a way that the water starts to flash to produce pure vapour. This vapour condenses around the condenser tube to produce distillate (freshwater). As the flashing brine would be still hot enough to boil again at slightly lower pressure, the flashing brine flows into the next stage and the flashing process is then repeated all the way down the plant. This is happened as the flashing brine flows in the consecutive stages where pressure is decreased proceeding from left to right. The process is repeated until the last stage. The accumulated distillate from all stages is finally collected in a distillate box at the last stage of the plant and is extracted by a distillate pump [12]. 


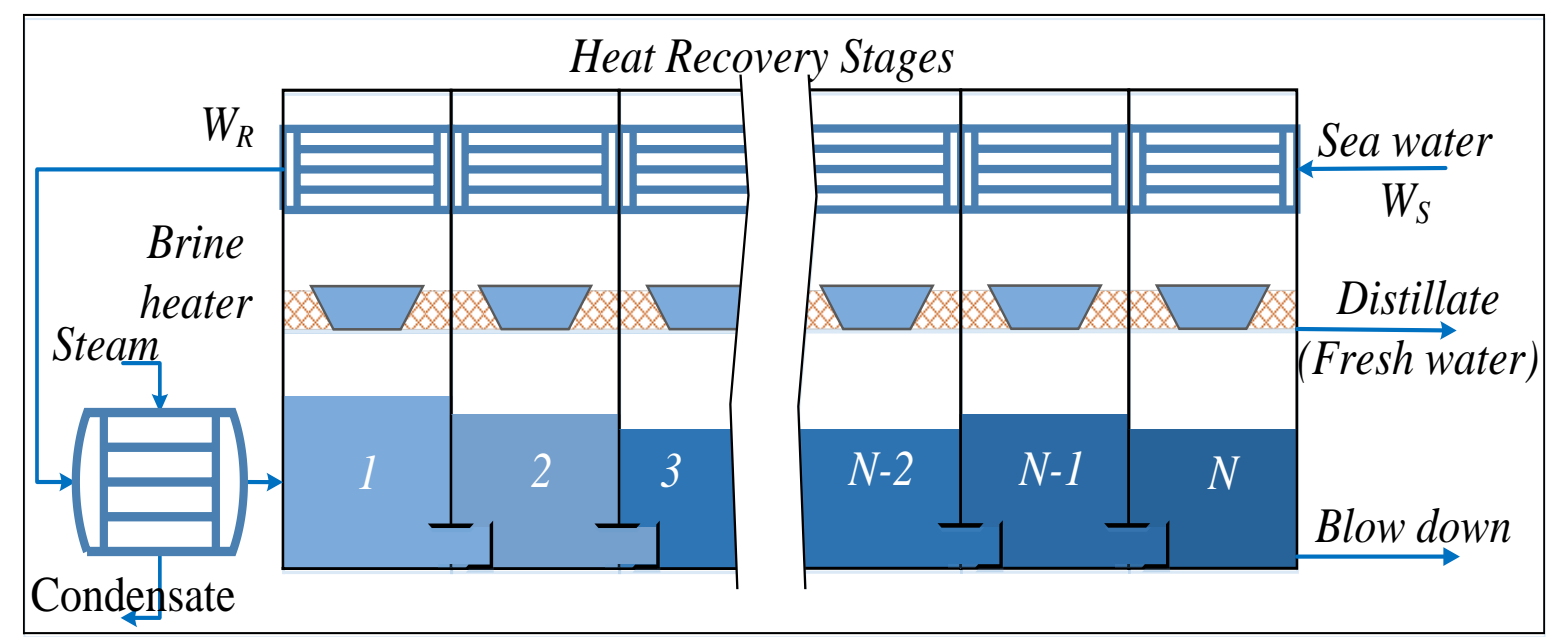

Figure 1: Schematic of Once through MSF desalination process (MSF-OT)

\section{Fouling Mechanism}

The calcium carbonate and magnesium hydroxide are known in practice as the alkaline scales. With the increase of the seawater temperature entering the MSF plant, a number of reactions take place as reported by several researchers:

$$
2 \mathrm{HCO}_{3}^{-} \leftrightarrow \mathrm{CO}_{2} \uparrow+\mathrm{CO}_{3}^{2-}+\mathrm{H}_{2} \mathrm{O}
$$

Shams El Din, et al. [13] and Mubarak [7] mentioned that the previous reaction can occur in two sequence steps namely:

$$
\mathrm{HCO}_{3}^{-} \rightarrow \mathrm{CO}_{2} \uparrow+\mathrm{OH}^{-}
$$

Followed by fast acid neutralization step

$$
\mathrm{OH}^{-}+\mathrm{HCO}_{3}^{-} \rightarrow \mathrm{CO}_{3}^{2-}+\mathrm{H}_{2} \mathrm{O}
$$

Segev, et al. [14] and Olderøy, et al. [15] reported that the aforementioned reactions (2 and 3) can be followed by other reactions like:

$$
\begin{aligned}
& \mathrm{HCO}_{3}^{-} \leftrightarrow \mathrm{CO}_{3}^{2-}+\mathrm{H}^{+} \uparrow \\
& \mathrm{H}^{+}+\mathrm{HCO}_{3}^{-} \leftrightarrow \mathrm{CO}_{2} \uparrow+\mathrm{H}_{2} \mathrm{O}
\end{aligned}
$$

However, reaction (5) was reported by Patel and Finan [16] and Shams El Din, et al. [13] as acidification reaction of seawater to mitigate the decomposition of $\mathrm{HCO}_{3}$.

In the presence of calcium ions, carbonate ions react with calcium ions to cause the deposit of $\mathrm{CaCO}_{3}$ once its solubility exceeds the limit.

$$
\mathrm{CO}_{3}^{2-}+\mathrm{Ca}^{2+} \rightarrow \mathrm{CaCO}_{3} \downarrow
$$

The summation of equations (2, 3 and 6) or equations $(4,5$ and 6) can lead to the same reaction equation that present the precipitation of $\mathrm{CaCO}_{3}$. 


$$
2 \mathrm{HCO}_{3}^{-}+\mathrm{Ca}^{2+} \rightarrow \mathrm{CaCO}_{3} \downarrow+\mathrm{CO}_{2} \uparrow+\mathrm{H}_{2} \mathrm{O}
$$

At higher temperature, in reverse to the reaction (3), the carbonate ions may hydrolyse to form bicarbonate according to the following reaction:

$$
\mathrm{CO}_{3}^{2-}+\mathrm{H}_{2} \mathrm{O} \rightarrow \mathrm{HCO}_{3}^{-}+\mathrm{OH}^{+}
$$

And, in the presence of magnesium, the resulting hydroxyl ions from reaction (8) can react with magnesium to cause the deposit of $\mathrm{Mg}(\mathrm{OH})_{2}$ once its solubility reach the limit.

$$
2 \mathrm{OH}^{-}+\mathrm{Mg}^{2+} \rightarrow \mathrm{Mg}(\mathrm{OH})_{2} \downarrow
$$

Comparing reaction (9) to reaction (3), Mubarak [7] reported that reaction (3) is faster than reaction (9) thought the precipitation of $\mathrm{Mg}(\mathrm{OH})_{2}$ is thermodynamically more favourable. Regarding to the calcium sulphate deposit, calcium and sulphate ions react to form calcium sulphate according to the following reaction:

$$
\mathrm{SO}_{4}^{2-}+\mathrm{Ca}^{2+} \rightarrow \mathrm{CaSO}_{4} \downarrow
$$

The reacting species such as $\left(\mathrm{Mg}^{2+}, \mathrm{Ca}^{2+}, \mathrm{CO}_{3}^{2-}, \mathrm{SO}^{2-}{ }_{4}, \mathrm{HCO}_{3}{ }^{-}, \mathrm{OH}^{-}\right)$are transferred towards the heat exchanger surface due to the diffusional phenomenon and react at the surface temperature resulting in deposition of fouling. When the deposit layer reaches a certain thickness, not only the reactant products would deposit but other species would start to stick due to the increase in the roughness of the surface. This explains the changeable structure of the fouling layer [17]. The released gases such as $\mathrm{CO}_{2}$, on the other hand are kept in solution and later are transferred away from the heat transfer surface and evaporated inside the flash chamber resulting in non-condensable gases around outside tubes bundle surface. More details of such gases can be found in Alsadaie and Mujtaba [18]. It is important to mention that the formation of $\mathrm{CO}_{2}$ inside the tubes leads to a decrease in the $\mathrm{pH}$ [9] and consequently lower the tendency of deposit to certain limit. However, as the brine enters the flash chambers, the $\mathrm{CO}_{2}$ released into the vapour space resulting in an increase in the $\mathrm{pH}$ and thus more deposit is expected in flash chambers.

\section{Fouling Model}

The proposed dynamic model considers the growth and removal rate of the fouling. The net deposit rate then can be calculated as the difference between the total deposition rate and the removal rate. The model also takes into account the physical properties of the seawater and the soluble species in the seawater.

In mathematical term, the net deposition rate may be estimated as the different between the total deposition rate and the removal rate.

$$
\frac{d m}{d t}=\frac{d m_{d}}{d t}-\frac{d m_{r}}{d t}
$$

\subsection{Total Deposit Rate}

Here, the following equation citied from ([19]) is proposed to predict the deposition rate for both calcium carbonate and magnesium hydroxide. The equation considers the kinetic and diffusion mechanisms of the species. 


$$
\frac{d m_{d}}{d t}=\beta\left[\frac{1}{2}\left(\frac{\beta \rho_{w} V^{2}}{k_{r} \mu_{w}}\right)+\left(C_{b}-C_{s}\right)-\sqrt{\frac{1}{4}\left(\frac{\beta \rho_{w} V^{2}}{k_{r} \mu_{w}}\right)^{2}+\left(\frac{\beta \rho_{w} V^{2}}{k_{r} \mu_{w}}\right)\left(C_{b}-C_{s}\right)}\right]
$$

The surface reaction rate constant $\left(k_{r}\right)$ can be obtained by Arrhenius rate equation.

$$
\text { Surface reaction rate: } \quad k_{r}=k_{r 0} \times e^{\left(-E a / R T_{s}\right)}
$$

The concentration driving force gradient $\left(C_{b}-C s\right)$ can be calculated as the different between the square root of the concentration of the reactants species and the square root of the $\mathrm{CaCO}_{3}$ solubility. For magnesium hydroxide, third root is used instead of square root.

$$
\begin{aligned}
& \text { Concentration gradient for } \mathrm{CaCO}_{3}: \quad\left(\mathrm{C}_{b}-C_{s}\right)=\left(\sqrt{[\mathrm{Ca}]\left[\mathrm{CO}_{3}\right]}-\sqrt{K_{s p}}\right) \\
& \text { Concentration gradient for } \mathrm{Mg}(\mathrm{OH})_{2}: \quad\left(C_{b}-C_{s}\right)=\left(\sqrt[3]{[\mathrm{Mg}][\mathrm{OH}]^{2}}-\sqrt[3]{K_{s p}}\right)
\end{aligned}
$$

\section{Solubility product:}

The standard solubility product of both calcium carbonate and magnesium hydroxide can be define by equations (16) and (17), respectively.

$$
\begin{aligned}
& \log \left(K_{\text {spСасо } 3}^{0}\right)=\left[-171.9773-0.077993 \times T_{s}+\frac{2903.293}{T_{s}}+71.595 \times \log \left(T_{s}\right)\right] \\
& \log \left(K_{\text {spMg }(\mathrm{OH}) 2}^{0}\right)=14.723-\frac{3472.3}{T_{s}}-0.04642 \times T_{s} \\
& \quad K_{s p}=K_{s p}^{0} /\left(\gamma_{i} \cdot \gamma_{j}\right)
\end{aligned}
$$

To investigate the effect of the seawater salinity on fouling, the activity coefficients of reactant species of foulants should be taken into consideration. Thus, in equation (18), the solubility product of the foulant is defined as the standard solubility product divided by the activity coefficient of the reactant species. For calcium carbonate, $\gamma_{i}$ and $\gamma_{j}$ are the activity coefficients of calcium and carbonate respectively.

$$
\text { Activity coefficient: } \log \left(\gamma_{i}\right)=-A z_{i}^{2} \frac{\sqrt{I}}{1+B a_{i} \sqrt{I}}+b_{i} I
$$

Ionic strength: $\quad I=1 / 2 \sum z_{i}^{2} m_{i}$

\subsection{Carbonate System Equations:}

The crystallisation of calcium carbonate on hot surface results in release of carbon dioxide causing the $\mathrm{pH}$ of the seawater to be increased. Thus, for given total alkalinity and total carbon dioxide, the $\mathrm{pH}$ of the seawater can be calculated using equation (21). (Note $\mathrm{pH}=-$ $\log \left(\mathrm{H}^{+}\right)$. 


$$
\begin{gathered}
{\left[H^{+}\right]^{3}+\left(T A+K_{1}\right)\left[H^{+}\right]^{2}+\left(T A . K_{1}+K_{1} \cdot K_{2}+K_{w}-T C . K_{1}\right)\left[H^{+}\right]} \\
-K_{1} \cdot K_{2} \cdot \frac{K_{w}}{\left[H^{+}\right]}+\left(T A . K_{1} \cdot K_{2}-K_{1} \cdot K_{w}-2 . T C . K_{1} \cdot K_{2}\right)=0 \\
\operatorname{Ln}\left(K_{1}\right)=2.18867-2275.035 / T_{s}-1.468591 \times \operatorname{Ln}\left(T_{s}\right)+ \\
\left(-0.138681-9.33291 / T_{s}\right) \times S^{0.5}+0.072648 \times S-0.00574938 \times S^{1.5} \\
\operatorname{Ln}\left(K_{2}\right)=-0.84226-3741.1288 / T_{s}-1.437139 \times \operatorname{Ln}\left(T_{s}\right)+ \\
\left(-0.128417-24.41239 / T_{s}\right) \times S^{0.5}+0.1195308 \times S-0.0091284 \times S^{1.5} \\
\operatorname{Ln}\left(K_{w}\right)=148.9802-13847.26 / T_{s}-23.6521 \times \operatorname{Ln}\left(T_{s}\right)+ \\
\left(-5.977-118.67 / T_{s}+1.0495 \times \operatorname{Ln}\left(T_{S}\right)\right) \times S^{0.5}-0.01615 \times S
\end{gathered}
$$

In hard water, the following equilibrium equations can be used to calculate the concentration of carbonate species.

$$
\begin{gathered}
{\left[\mathrm{OH}^{-}\right]=K_{w} /\left[\mathrm{H}^{+}\right]} \\
{\left[\mathrm{HCO}^{-}\right]=\frac{T A+\left[\mathrm{H}^{+}\right]-\left[\mathrm{OH}^{-}\right]}{\left(1+2 \times K_{2} /\left[\mathrm{H}^{+}\right]\right)}} \\
{\left[\mathrm{CO}^{2-}\right]=\frac{T A+\left[\mathrm{H}^{+}\right]-\left[\mathrm{OH}^{-}\right]}{2 \times\left(1+\left[\mathrm{H}^{+}\right] / 2 \mathrm{~K}_{2}\right)}} \\
{\left[\mathrm{CO}^{2}\right]=\frac{\left[\mathrm{H}^{+}\right]}{K_{1}} \times \frac{T A+\left[\mathrm{H}^{+}\right]-\left[\mathrm{OH}^{-}\right]}{\left(1+2 \times K_{2} /\left[\mathrm{H}^{+}\right]\right)}}
\end{gathered}
$$

The TA in equivalents per litre is equal to:

$$
\mathrm{TA}=\left[\mathrm{HCO}_{3}^{-}\right]+2\left[\mathrm{CO}_{3}^{2-}\right]+\left[\mathrm{OH}^{-}\right]-\left[\mathrm{H}^{+}\right]
$$

and TC is equal to:

$$
\mathrm{TC}=\left[\mathrm{HCO}_{3}^{-}\right]+\left[\mathrm{CO}_{3}^{2-}\right]+\left[\mathrm{CO}_{2}\right]
$$

\subsection{Removal Rate}

As the thickness of the fouling layer increase, another mechanism starts to play an important role in slowing or limiting the increase in the fouling thickness. This is called removal rate mechanism which is affected directly or indirectly by several parameters such as wall stress of the bulk flow, $\tau_{\mathrm{f}}$, shear strength of the fouling layer, $\sigma_{\mathrm{f}}$ and density of the fouling layer, $\rho_{\mathrm{f}}$.

$$
\frac{d m_{r}}{d t}=k_{r e m} \frac{\tau_{f}}{\sigma_{f}} \rho_{f}\left(\frac{\mu_{w} g}{\rho_{w}}\right)^{1 / 3}
$$


It is important to mention that the fouling layer density depends on the thickness of the fouling layer. As the fouling thickness increases, the porosity of the layer increases resulting in a decrease in fouling layer density [20]. The change in the fouling layer density due to porosity also affect the conductivity of the fouling layer. Thus, the conductivity of the layer should be taken as the average between the compact solid and water depending on the porosity of the layer.

\subsection{Fouling Resistance}

The fouling resistance can be determined as function of the net deposit rate, the density of the fouling layer and the conductivity of the fouling layer. Then the fouling resistance is introduced into the overall heat transfer coefficient.

$$
\begin{aligned}
& \frac{d R_{f}}{d t}=\frac{1}{\lambda_{f} \times \rho_{f}} \times\left[\frac{d_{m d}}{d t}-\frac{d_{m r}}{d t}\right] \\
& \frac{1}{U_{o}}=\left(\frac{d_{o}}{h_{i} d_{i}}\right)+\left(R_{f, i} \frac{d_{o}}{d_{i}}\right)+\left(\frac{d_{o}}{2 k_{t}}\right) \operatorname{Ln}\left(\frac{d_{o}}{d_{i}}\right)+R_{f, o}+\left(\frac{1}{h_{o}}\right)
\end{aligned}
$$

\subsection{Water boxes connections}

As the seawater flows from stage tube bundle to another, the concentration of the seawater species decreases due to the fouling deposition. Thus, the concentration of the seawater species in the next few stages can be determined by the following equations:

$$
\begin{aligned}
C a_{(j+1)} & =C a_{(j)}-\mathrm{CaCO}_{3(j)} \\
M g_{(j+1)} & =M g_{(j)}-M g(O H)_{2(j)} \\
T A_{(j+1)} & =T A_{(j)}-\mathrm{CaCO}_{3(j)}-1 / 2 M g(O H)_{2(j)} \\
T C_{(j+1)} & =T C_{(j)}-\mathrm{CaCO}_{3(j)}
\end{aligned}
$$

More details of the model equations can be found in Alsadaie and Mujtaba [10].

\section{Results and Discussions}

The proposed dynamic fouling model is coded using gPROMS model builder v4.2 and then embedded into MSF-OT process dynamic model. The seawater temperature, top brine temperature, flowrate and salinity concentration of the intake seawater are varied to observe their effect on the fouling behaviour. The chemical composition of the intake seawater that used in this work is presented in Table 1. 
Table 1: Chemical composition of the intake seawater [9].

\begin{tabular}{lll}
\hline Parameters & Unit & Seawater to the plant \\
\hline $\mathrm{pH}$ & & 8.2 \\
\hline Conductivity & $\mu \mathrm{S} / \mathrm{cm}$ & 58000 \\
\hline Total alkalinity & $\mathrm{mg} / \mathrm{L}$ as $\mathrm{CaCO}_{3}$ & 128 \\
\hline TDS & $\mathrm{mg} / \mathrm{L}$ & 44000 \\
\hline Total hardness & $\mathrm{mg} / \mathrm{L}$ & 6700 \\
\hline Sulphate & $\mathrm{mg} / \mathrm{L}$ & 3200 \\
\hline Calcium & $\mathrm{mg} / \mathrm{L}$ & 490 \\
\hline Magnesium & $\mathrm{mg} / \mathrm{L}$ & 1420 \\
\hline
\end{tabular}

The simulation of MSF-OT process is run for a period of 100 days (assuming no use of antiscalant) to observe any possible deposition of calcium carbonate and magnesium hydroxide inside the condenser tubes. As the reactions (6) and (9) occur, the calcium carbonate and magnesium hydroxide start to precipitate on the internal surface of the tubes as their solubility limits are exceeded. Figure 2 shows the solubility products of calcium carbonate and magnesium against the number of stages. As the intake seawater flows from stage 21 to stage 1 , its temperature increases and consequently the solubility products of the foulants decrease resulting in an increase in the deposition rates of calcium carbonate and magnesium hydroxide. The presented solubility products of the foulants (calcium carbonate and magnesium hydroxide) are calculated based in equations (16-20).

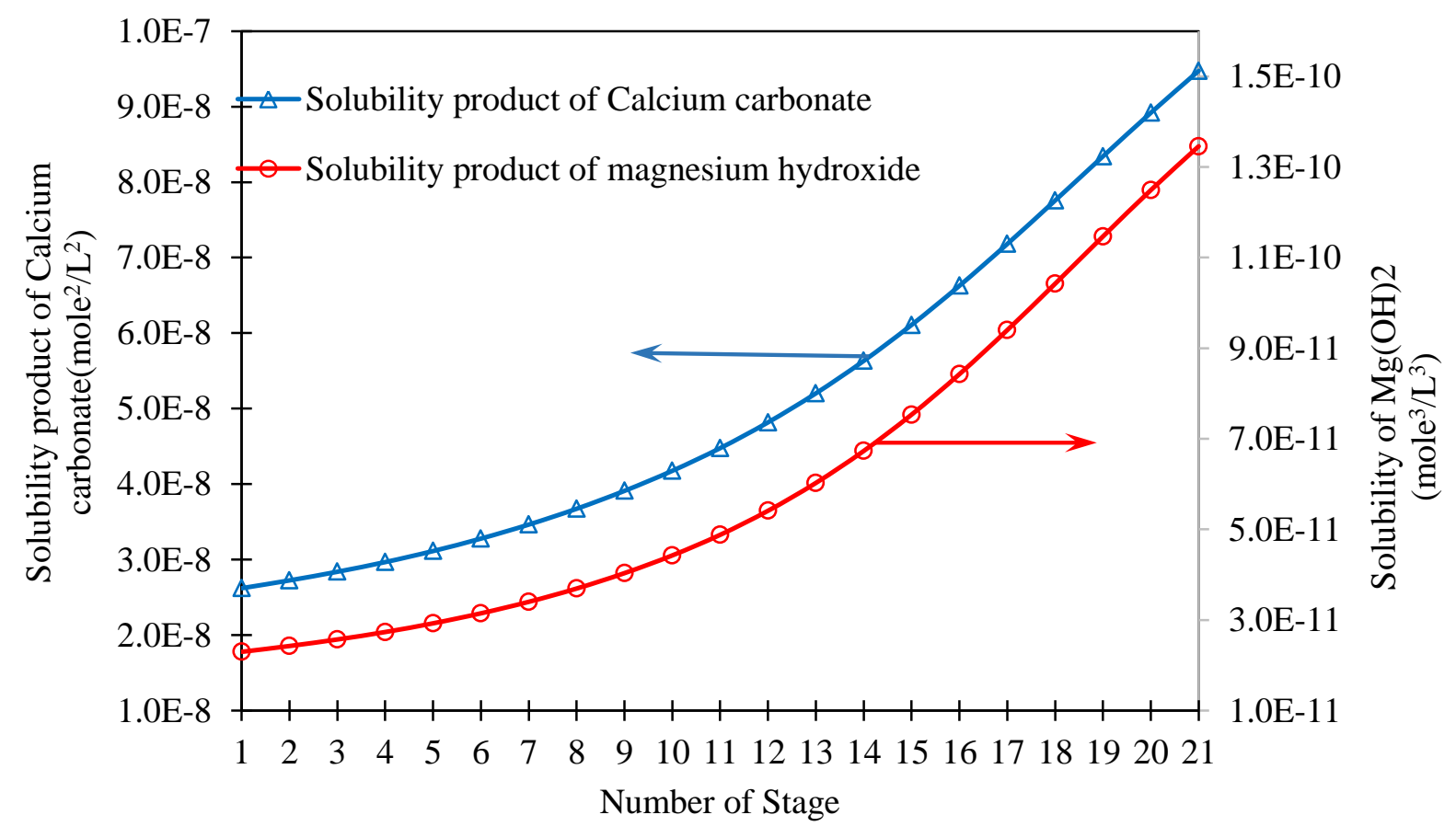


Figure 2: Solubility products of calcium carbonate and magnesium hydroxide.

Figure 3 shows the rate of deposition of calcium carbonate and magnesium hydroxide per unit area against stages number. The gradual increase in the surface temperature from one stage to other, increases the crystallization of $\mathrm{CaCO}_{3}$ and $\mathrm{Mg}(\mathrm{OH})_{2}$ (backward from stage 21 to the first stage). As mentioned in the introduction, the calcium carbonate has higher tendency of crystallization at lower temperature than magnesium hydroxide and thus the crystallization of calcium carbonate starts to occur at earlier stages while magnesium hydroxide starts to crystallize in the middle stages where the temperature reaches over $60{ }^{\circ} \mathrm{C}$. However, as it can be seen in figure 3, the crystallization rates of both components $\left(\mathrm{CaCO}_{3}\right.$ and $\mathrm{Mg}\left(\mathrm{OH}_{2}\right)$ starts to decrease due to the increase in the thickness of the fouling layer which leads to the reduction in the surface temperature. As the fouling is built up, it works as insulated materials resulting in reduction of the heat flux through the pipe and fouling layer materials and thus the surface temperature decreases.

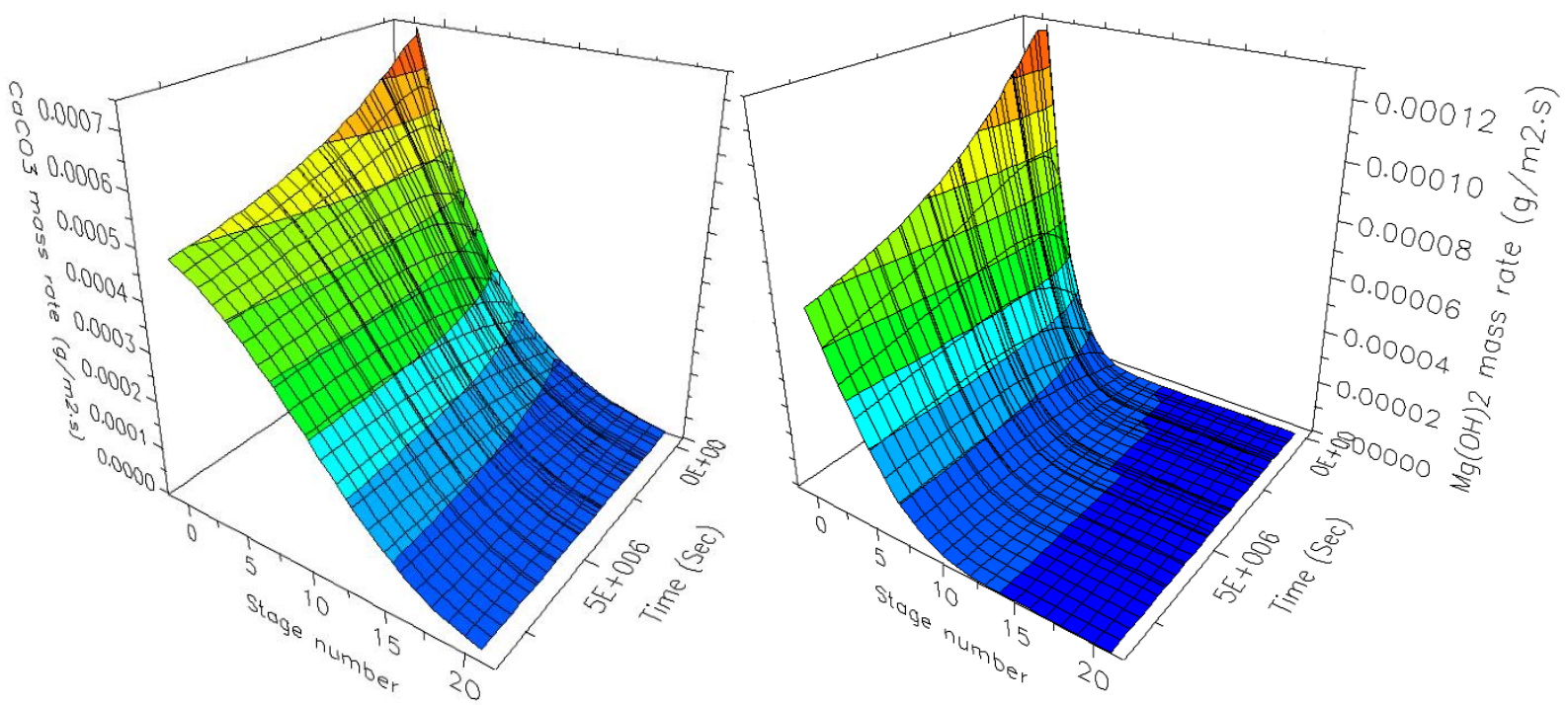

Figure 3: Calcium carbonate mass rate (left) and magnesium hydroxide mass rate (right)

Figure 4 presents the total deposit rate, the removal rate and the net deposit rate per unit area for the first stage. The first stage is chosen here because it has the highest temperature compared to the other stages and thus it would be the right choice to observe the behaviour of deposition and removal rates clearly. Increasing the accumulation of fouling inside the condenser tubes leads to increase the thickness of the fouling layer and consequently the surface temperature inside the tubes drops due to the low conductivity of the fouling layer. Therefore, the reduction of the surface temperature results in a decrease in the rate of deposition. However, on the other hand, increasing the thickness of the fouling layer causes reduction in the cross section area of the tubes resulting in increase in the flow velocity and consequently the removal rate increases. Moreover, as it can be seen from figure 4, the behaviour of the net deposit rate is nonlinear as it starts to decrease in slightly constant rate and then gradually reaches steady state after a certain time. At the initial stage of fouling, the heat flux is high resulting in high deposition rate with almost negligible removal rate. However, as the thickness of the fouling layer increases, the surface roughness increases causing the velocity of the bulk fluid to play the role in increasing the removal rate according 
to the equation (31). Although increasing the roughness of the surface increases the probability of the sticky particles to deposit, the drop in the surface temperature due to fouling slows the increase in the deposition rate. Thus, the removal rate increases faster than the deposition rate and after certain time, both rates (removal rate and the deposition rate) stop increasing and become equal resulting in a constant value of net deposition rate. Similar results, as presented in Figure 4, have been obtained by Brahim et al,. [21].

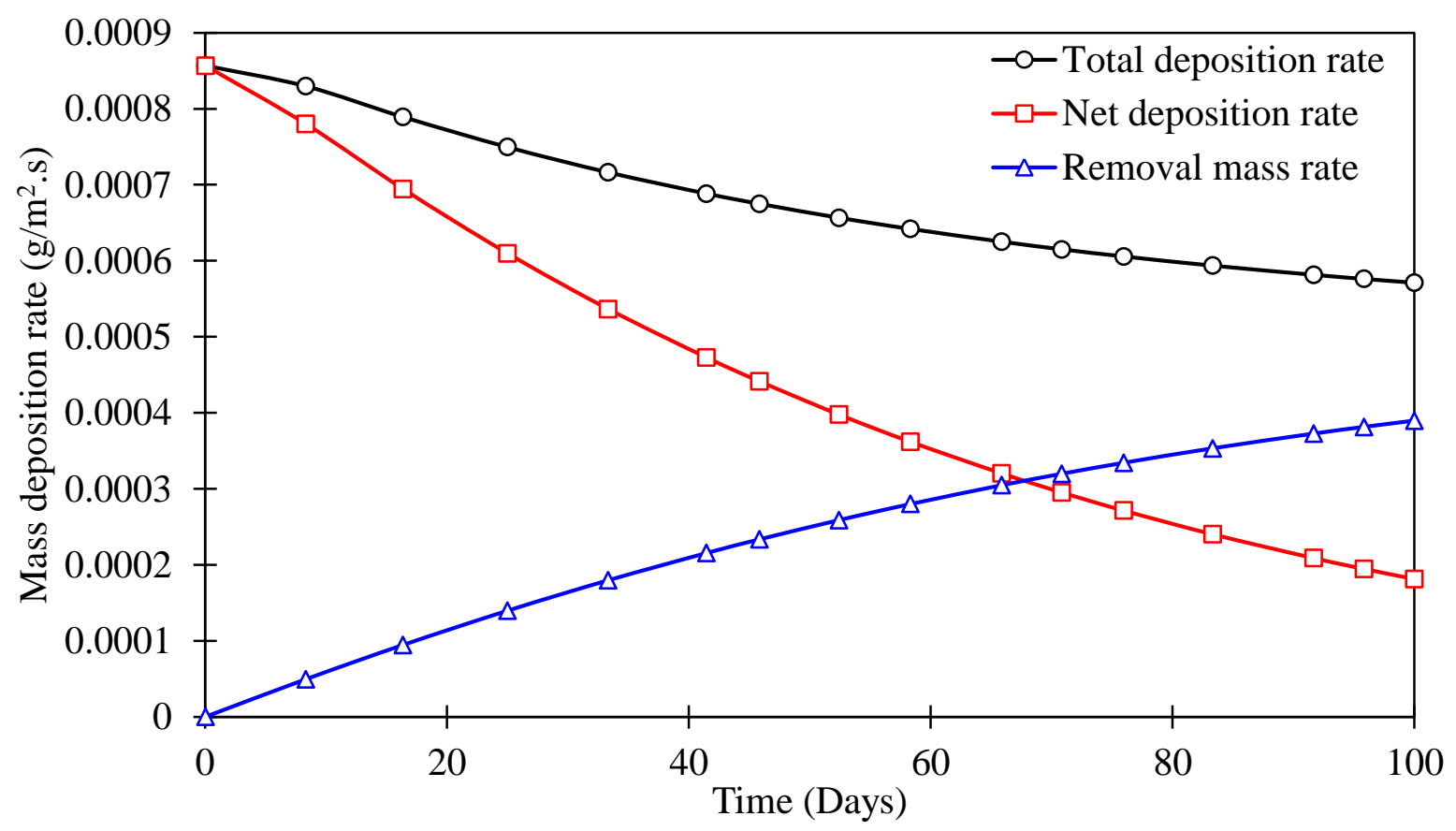

Figure 4: Total deposit rate together with removal rate and net rate per unit area.

\subsection{Effect of Seawater Temperature}

The main drawback of the MSF-OT process is the absence of the intake seawater temperature control. Typically, the seawater temperature is affected by locality and the seasonal climatic change when it could drop to below $20{ }^{\circ} \mathrm{C}$ in winter and could exceed $30{ }^{\circ} \mathrm{C}$ in summer. Hawaidi and Mujtaba [6] reported an increase in the fouling formation inside the brine heater due to the change in seawater temperatures, and thus, this behavior is expected to occur inside the condensers tubes. Therefore, to confirm that, three temperature values $\left(20{ }^{\circ} \mathrm{C}, 25{ }^{\circ} \mathrm{C}\right.$ and $30{ }^{\circ} \mathrm{C}$ ) are tested to investigate their effect on the crystallization of $\mathrm{CaCO}_{3}$ and $\mathrm{Mg}(\mathrm{OH})_{2}$. Figure 5 shows that increasing the seawater temperature leads to slight increase in the crystallization rate of $\mathrm{CaCO}_{3}$. However, the effect can be seen clearly in the middle stages because the effect of the intake seawater temperature is stronger on the stages that close to the feed entrance where the Log Mean Different Temperature (LMDT) is higher. As the seawater flows towards the first stage, the effect of the TBT becomes stronger and has greater control on the temperature inside the tubes. Since the TBT is constant in this case, the outlet temperature of the first stage is nearly constant and either the deposition rate of $\mathrm{CaCO}_{3}$ despite the variation of the intake seawater temperature. Similar behaviour can be seen for magnesium hydroxide as shown in figure 6. However, the crystallization rate of magnesium hydroxide increases through most of stages include the first stage where the temperature changes very slightly. The reason is that the crystallization of $\mathrm{Mg}(\mathrm{OH})_{2}$ is very sensitive to the temperature variation due to its low solubility compared to $\mathrm{CaCO}_{3}$. It is important to mention that figures 5 and 6 were plotted for steady state operation after 40 days of operation. 


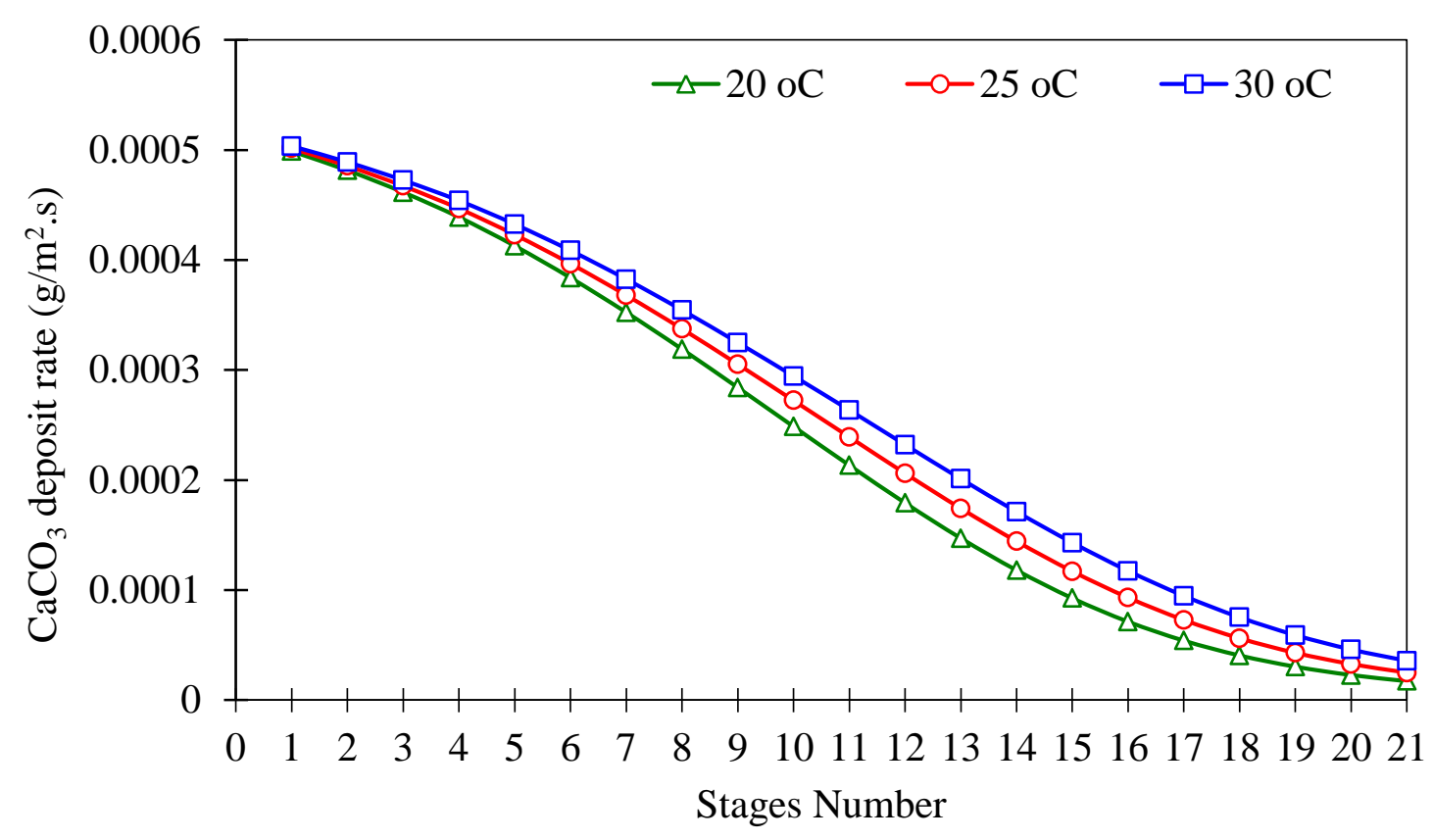

Figure 5: Effect of the seawater temperature on the rate of deposition of $\mathrm{CaCO}_{3}$.

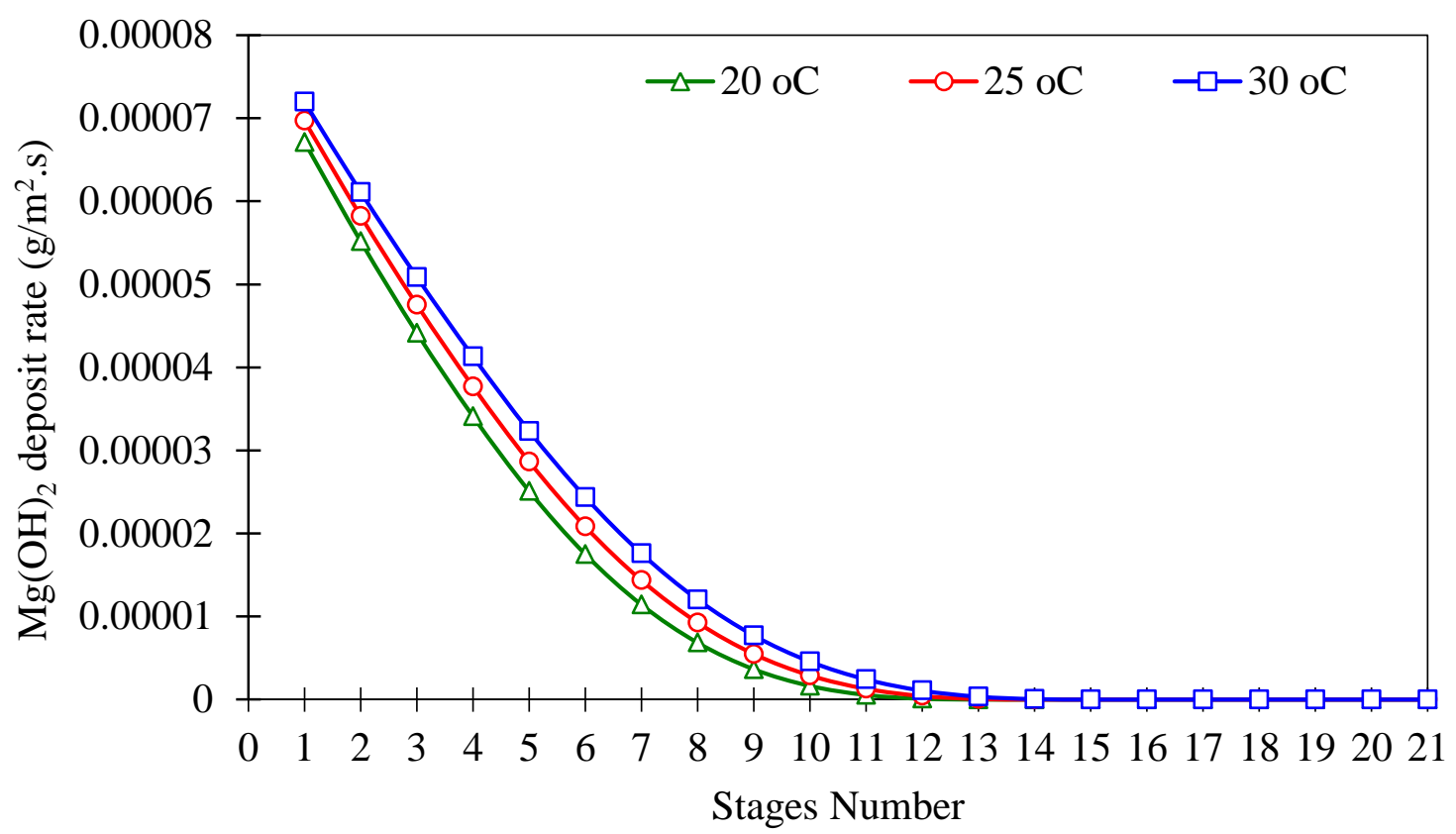

Figure 6: Effect of the seawater temperature on the rate of deposition of $\mathrm{Mg}(\mathrm{OH})_{2}$.

\subsection{Effect of Top Brine Temperature}

Top brine temperature (TBT) is the temperature of the recirculation brine after it is heated by the low-pressure steam in the brine heater. It plays an important role in describing the performance of MSF process. It has direct effects on the distillate production and the levels in each flash chamber [22]. Most of the multistage flash desalination plants (MSF) operate at top brine temperatures (TBT) of $90-120{ }^{\circ} \mathrm{C}$ [6]. Selecting the operating temperature of TBT depends on different parameters such as specific design of the MSF plants and the salinity and temperature of the intake seawater. Though operating the plant at the higher temperature limits of $120{ }^{\circ} \mathrm{C}$ tends to increase the efficiency; however it also increases the potential for fouling formation inside the MSF plant [23]. It is important to note that the previous 
presented results were obtained at $\mathrm{TBT}=90{ }^{\circ} \mathrm{C}$ (Base case). In this section, an incremental 10 ${ }^{\circ} \mathrm{C}$ is made up to $120{ }^{\circ} \mathrm{C}$ to observe the effect of TBT on the crystallization rates of calcium carbonate and magnesium hydroxide. Figure 7 and 8 show the rate of deposition of calcium carbonate and magnesium hydroxide respectively. Here, the simulation is run for a period of only 30 days to avoid any infeasible results at higher temperature caused by large increase in the fouling rate. Moreover, the crystallization rates are plotted at steady state point (at the end of 30 days period) against the stages number to see the behaviour of crystallization with temperature in all stages. As it can be seen, both calcium carbonate and magnesium hydroxide deposition rates increase with the increase in the TBT. However, with the increase in the TBT, the behaviour of the crystallization rate of calcium carbonate per stages changes as the surface temperature of the middle stages starts to increase. This can be explained by the simultaneous effect of velocity and temperature. As the fouling increases due to the increase in the surface temperature, the fouling layer thickness increases as well resulting in increase in the flow velocity inside the tubes. Thus, high velocity in the first few stages limits or slows down the crystallization rate of calcium carbonate. Moreover, the increase in the fouling in the first few stages leads to reduction in heat flux from the vapour to the seawater inside the tubes. This results in increase in the temperature of the brine flows to the next stages. As results, more crystallization occurs in the middle stages due to the increase in the surface temperature. In addition, the velocity in the middle stages is less than the velocity in the first few stages and thus the influence of the temperature in these stages is more than the impact of the velocity. Also, increasing the crystallization rate of calcium carbonate in the middle stages may lead to reduction of calcium and carbonate ions in the seawater flows inside the tubes to the first few stages and thus results in reduction in the crystallization of calcium carbonate in these stages.

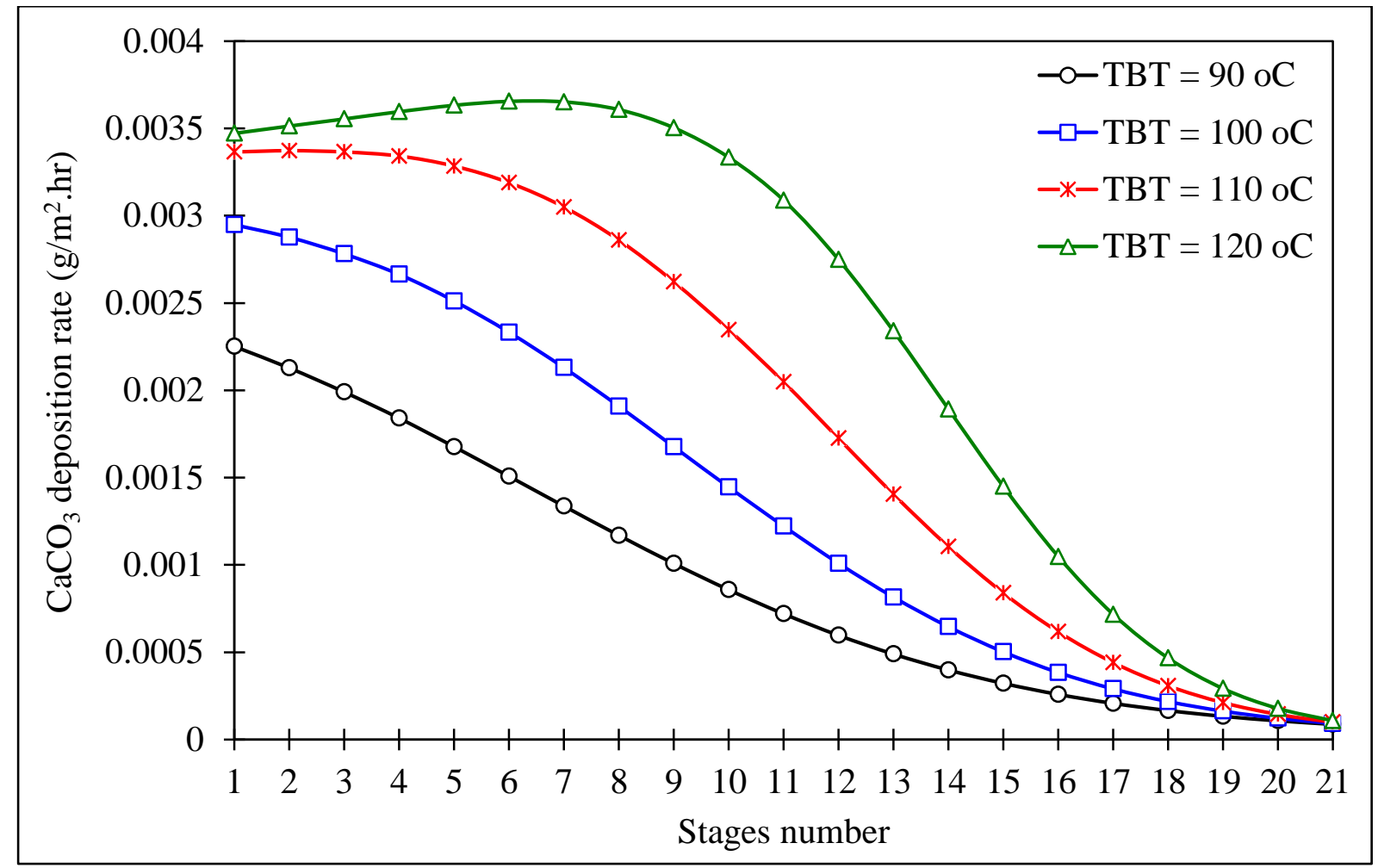

Figure 7: Effect of the TBT on the rate of deposition of $\mathrm{CaCO}_{3}$ per stages (30 days).

Similar behaviour can be obtained for magnesium hydroxide. As it can be seen from figure 8 , the crystallization of magnesium hydroxide increases with the increase in the TBT. However, due to low solubility of the magnesium hydroxide compared to calcium carbonate, its 
crystallization rate is more sensitive to the temperature and thus increases as long as the temperature increases. Moreover, as reported by Dooly and Glater [24], the crystallization rates of calcium carbonate and magnesium hydroxide depend on the $\mathrm{Ca} / \mathrm{Mg}$ and $\mathrm{CO}_{3} / \mathrm{OH}$ ratio. Increasing $\mathrm{Ca} / \mathrm{Mg}$ or $\mathrm{CO}_{3} / \mathrm{OH}$ ratio leads to calcium carbonate to becomes more favourable over magnesium hydroxide. Thus, the increasing crystallization of calcium carbonate in the middle stages as shown in figure 7 leads to reduction in $\mathrm{Ca}$ and $\mathrm{CO}_{3}$ transported to the next stages (first few stages) and hence crystallization of magnesium hydroxide become more favourable due to decrease in the $\mathrm{Ca} / \mathrm{Mg}$ and $\mathrm{CO}_{3} / \mathrm{OH}$ ratio.

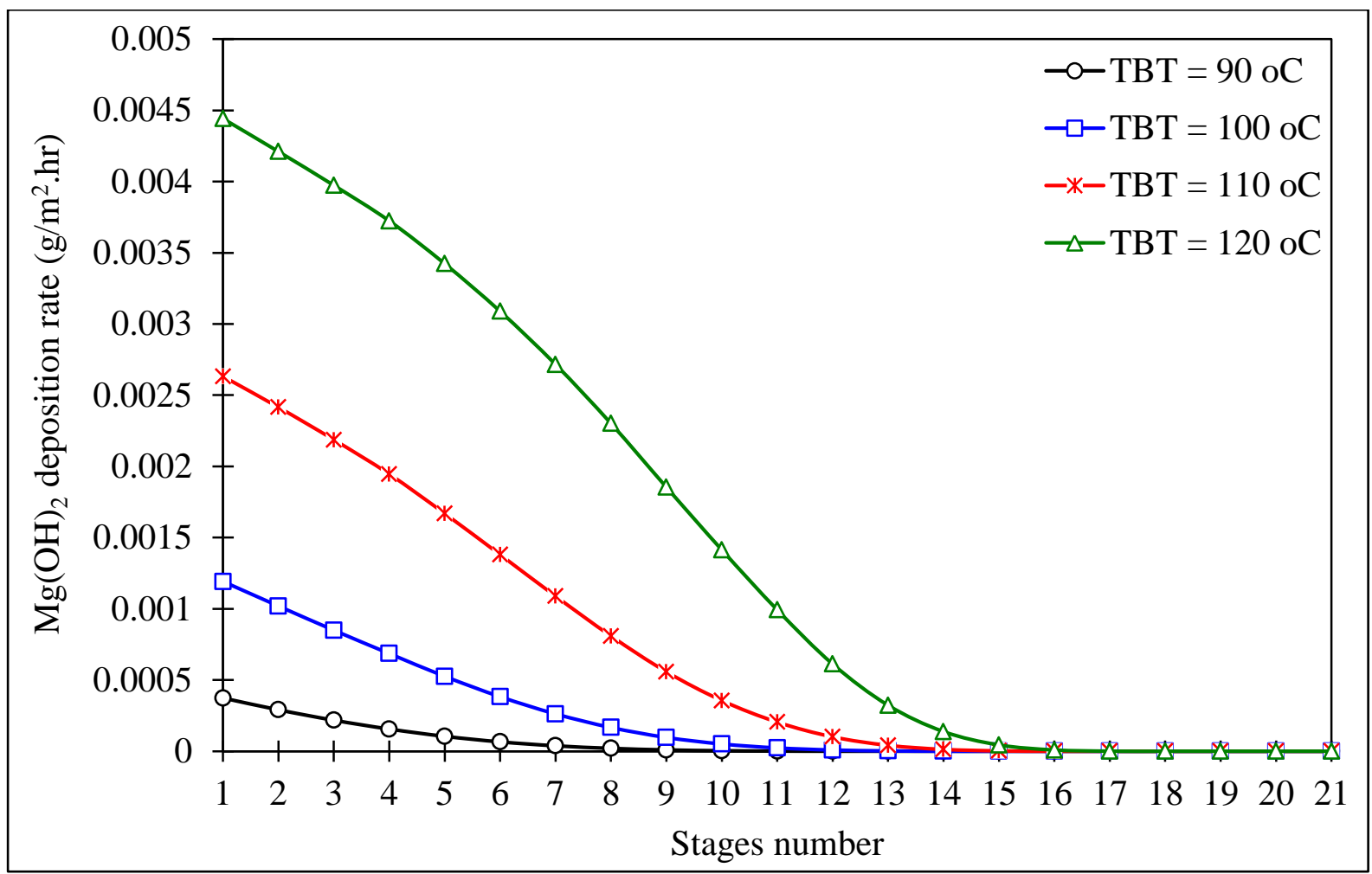

Figure 8: Effect of the TBT on the rate of deposition of $\mathrm{Mg}(\mathrm{OH})_{2}$ per stages (30 days)

It is well known that increasing the TBT results in increase in the performance ratio of the plant. The performance ratio (PR) is defined as the amound of produced distillate per $1 \mathrm{~kg}$ of consumed steam in the brine heater. However, the main obstacle that refrain the MSF plants from operating at high temperature is the increase in the accumulation of fouling inside the condenser tubes due to high temperature. Here, the performnace ratio is plotted for 4 different TBT values to observe the behaviour of the perfromance ratio under fouling at varied TBT temperatures. Without antiscalants, infeasible results are expected at higher temperature due to large increase in the fouling rate. Thus, the model is run only for 60 days. As it can be seen from figure 9, increasing the TBT results in an initial increase in the performance ratio. However, this increase can only last for short period (approxamitly two days) before the impact of fouling takes control of the process and cause a very sudden decrease in the performance ratio. Hence, a pretreatment of the intake seawater by minimizing the concentration of divalent ions such as $\mathrm{Ca}^{2+}$ and $\mathrm{Mg}^{2+}$ may open the oppoutinuty for the MSF industry to operate at higher temperature. 


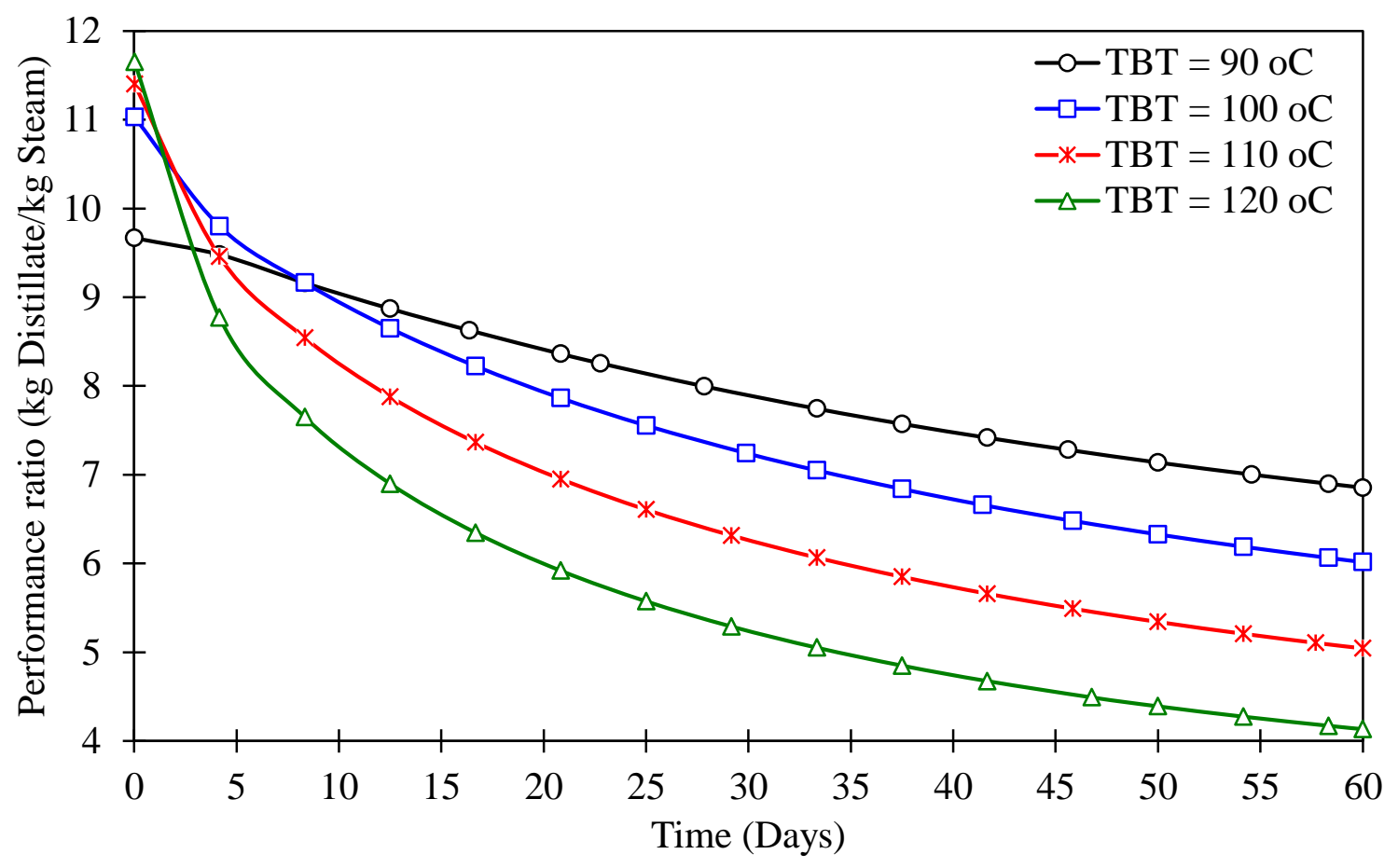

Figure 9: Effect of the TBT on the performance ratio under fouling.

\subsection{Effect Seawater Flowrate}

Variation of the seawater flowrate results in variation in the seawater velocity inside the tubes. Moreover, the velocity at constant flow rate may also vary as well due to the reduction of the cross section area of the tube caused by the increase in thickness of the fouling layer. Here, three values of the intake seawater flowrates $\left(3.2 \mathrm{~m}^{3} / \mathrm{s}, 3.6 \mathrm{~m}^{3} / \mathrm{s}\right.$ and $\left.4 \mathrm{~m}^{3} / \mathrm{s}\right)$ were considered to investigate their effect on fouling. As it can be seen in figures 10 and 11, the crystallization of $\mathrm{CaCO}_{3}$ and $\mathrm{Mg}(\mathrm{OH})_{2}$ decreases with the increase in the flowrate. Helalizadeh, et al. [25] and Fahiminia, et al. [26] reported that the mass diffusion rate has strong effect on the fouling at low velocities. However, as the velocity increases, the effect of mass diffusion rate is neglected and the fouling process is no longer controlled by diffusion mechanism. Since the deposit rate equation (Eq. 11) is function of the mass diffusion rate and flow velocity, thus, as reported by Pääkkönen, et al. [19], the deposition rate increases as the residence time increases (low velocity) and decreases as the residence time decreases (high velocity). Therefore, the behaviour of deposition rate of calcium carbonate and magnesium hydroxide in figures 10 and 11 can be explained by the strong effect of the velocity and the reduction of the resident time of the species to transfer to the surface than the effect of the mass diffusion rate. In addition, this result confirms the findings in section (5.2) where the increase in the temperature increases the tendency of fouling while the increase in the velocity reduces the crystallization of calcium carbonate. 


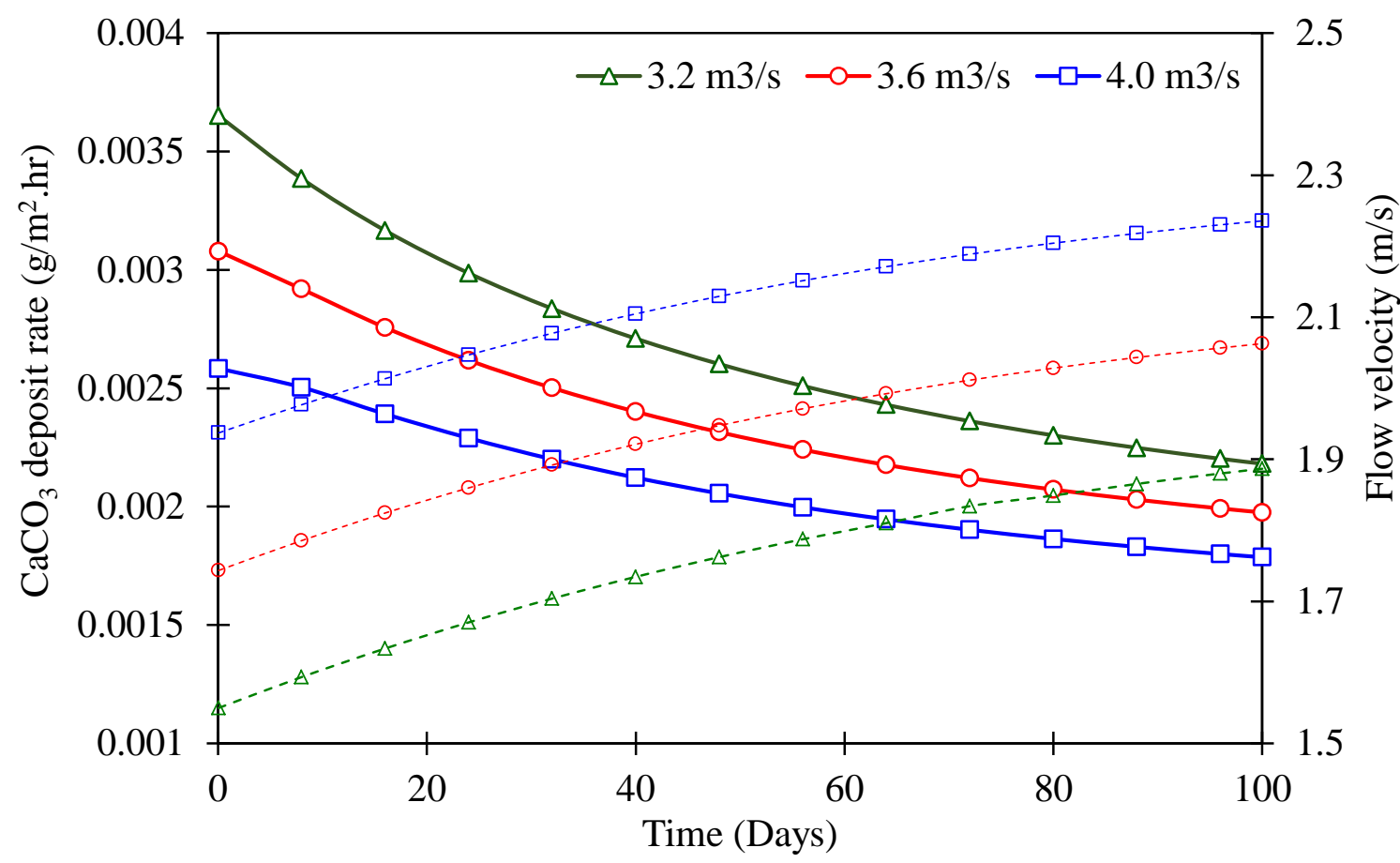

Figure 10: Velocity effect on the deposition rate of $\mathrm{CaCO}_{3}$ in the first stage.

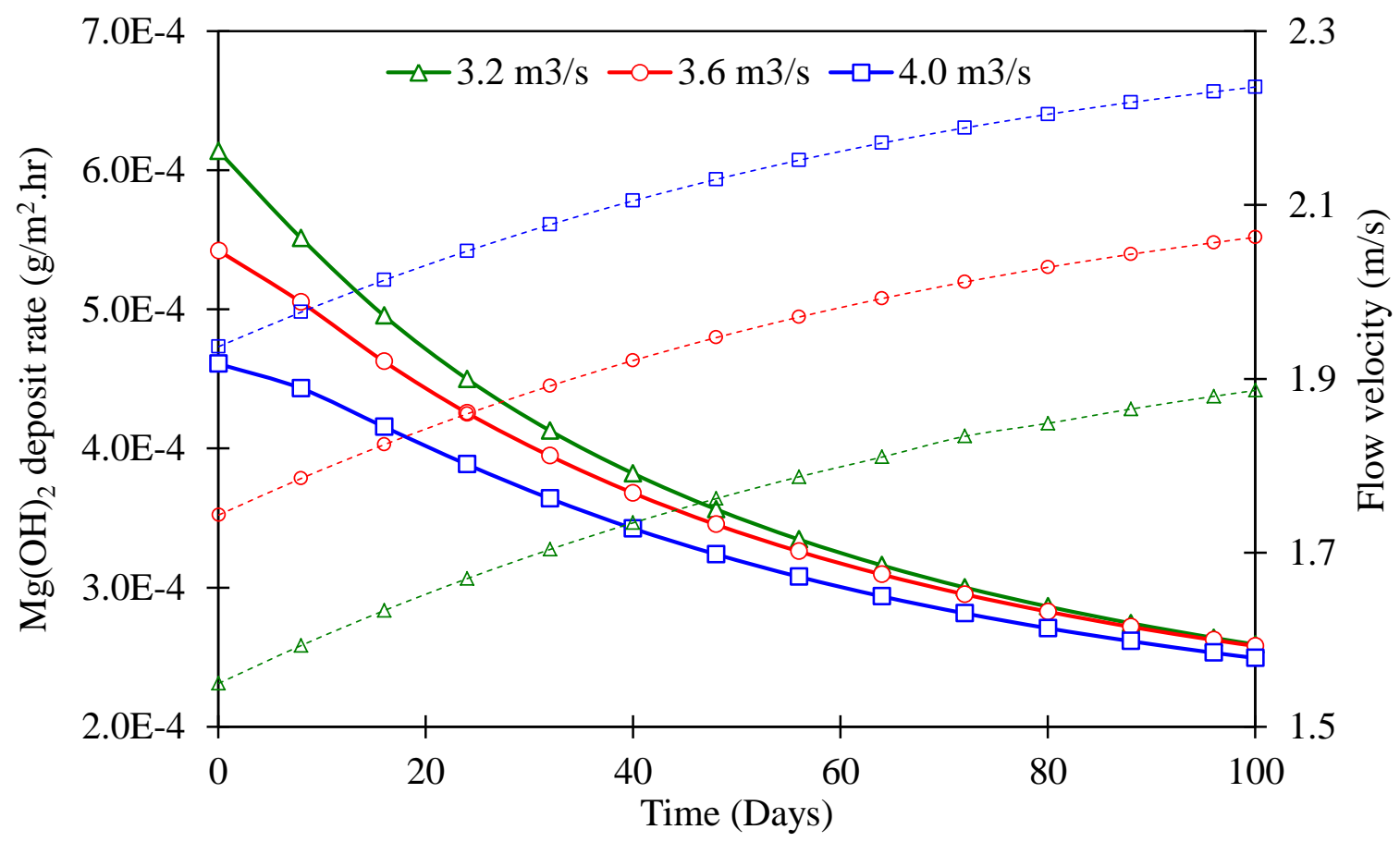

Figure 11: Velocity effect on the deposition rate of $\mathrm{Mg}(\mathrm{OH})_{2}$ in the first stage.

In comparison to the work developed by Alsadaie and Mujtaba [10] for MSF-BR process, two different flow rates $\left(3.5 \mathrm{~m}^{3} / \mathrm{s}\right.$ and $\left.4.0 \mathrm{~m}^{3} / \mathrm{s}\right)$ are investigated to explore the behaviour of the two models. Figure 12 presents the deposition rate of $\mathrm{Mg}(\mathrm{OH})_{2}$ in MSF-OT process using this model and the results obtained from Alsadaie and Mujtaba [10] for MSF-BR process at two different flow rates. As it can be seen, using the model developed by Alsadaie and Mujtaba [10] showed no noticeable change in the deposition rate of $\operatorname{Mg}(\mathrm{OH})_{2}$ as the flow rate increases. This is simply because their model only considered the kinetic mechanism and neglected the mass diffusion mechanism. Thus, for accurate results, it is important to include the mass diffusion rate in describing mathematically the deposition rate of any species on hot 
tubes. However, unlike calcium carbonate, the deposition rate of $\mathrm{Mg}(\mathrm{OH})_{2}$ is higher in MSFOT process than in the MSF-BR process. This may be explained by the reaction mechanism describe in equations (2) and (3). Dooly and Glater [24] pointed out the crystallization of $\mathrm{Mg}(\mathrm{OH})_{2}$ occurs simultaneously as $\left(\mathrm{OH}^{-}\right)$released. Thus, here, it is expected that reaction (9) occurs faster than reaction (3) resulting in crystallization of $\mathrm{Mg}(\mathrm{OH})_{2}$. Moreover, Mubarak [7] mentioned that the crystallization of $\mathrm{Mg}(\mathrm{OH})_{2}$ (reaction 2) is more favourable thermodynamically over reaction (3).

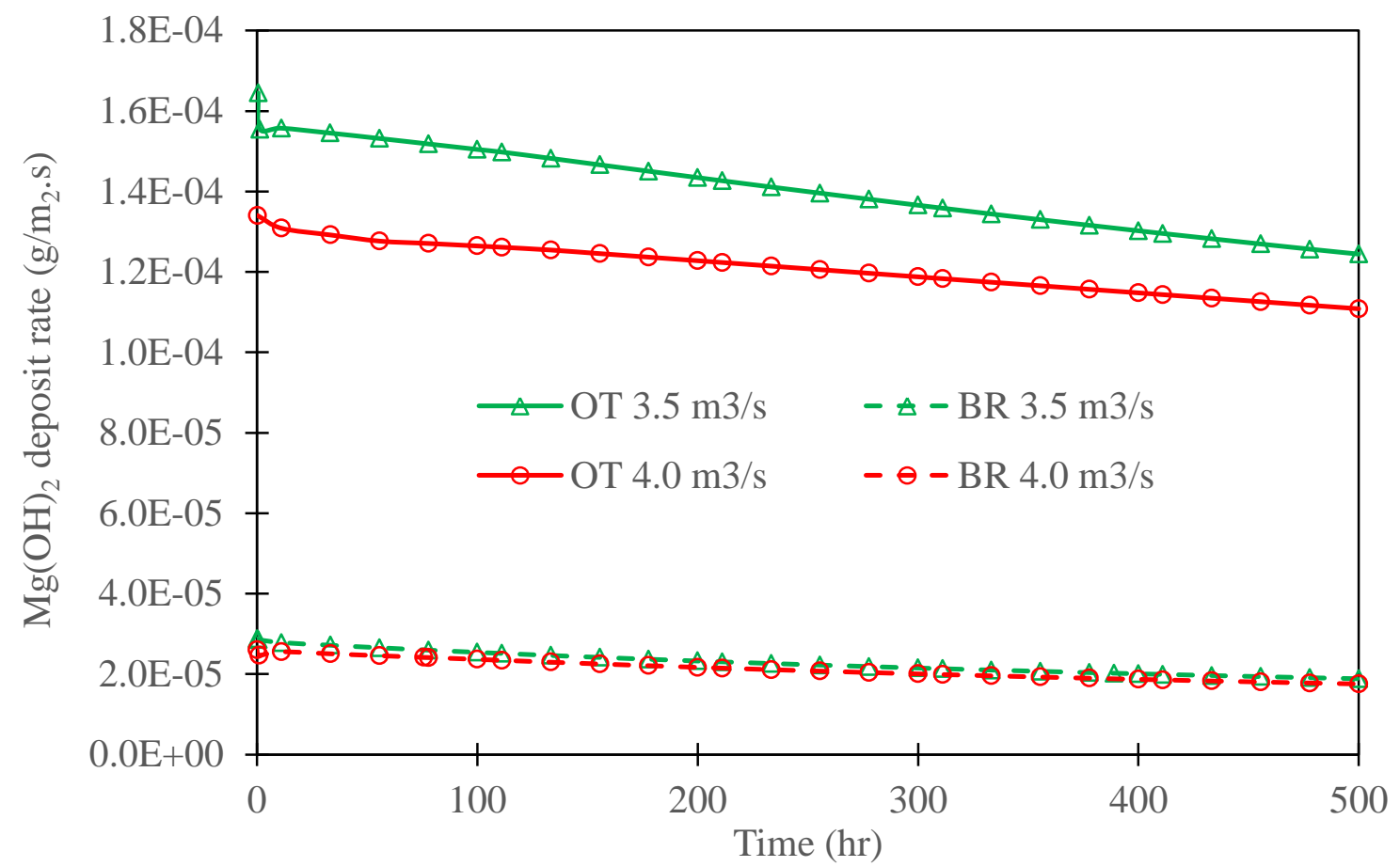

Figure 12: Flow rate effect on the deposition rate of $\mathrm{Mg}(\mathrm{OH})_{2}$ in the first stage in MSF-OT and MSF-BR processes.

Figure 13 shows the crystallization of calcium carbonate in MSF-OT and MSF-BR processes as the flow rate of the seawater increases. Due to the low salinity in MSF-OT, the deposition of calcium carbonate is less in MSF-OT process than in MSF-BR process. Moreover, the crystallization of calcium carbonate decreases as the flow rate increases. Similar pattern in the deposition change is obtained in both MSF-OT and MSF-BR processes. Simply because the deposition of calcium carbonate is described in similar equation as reported by Alsadaie and Mujtaba [10]. 


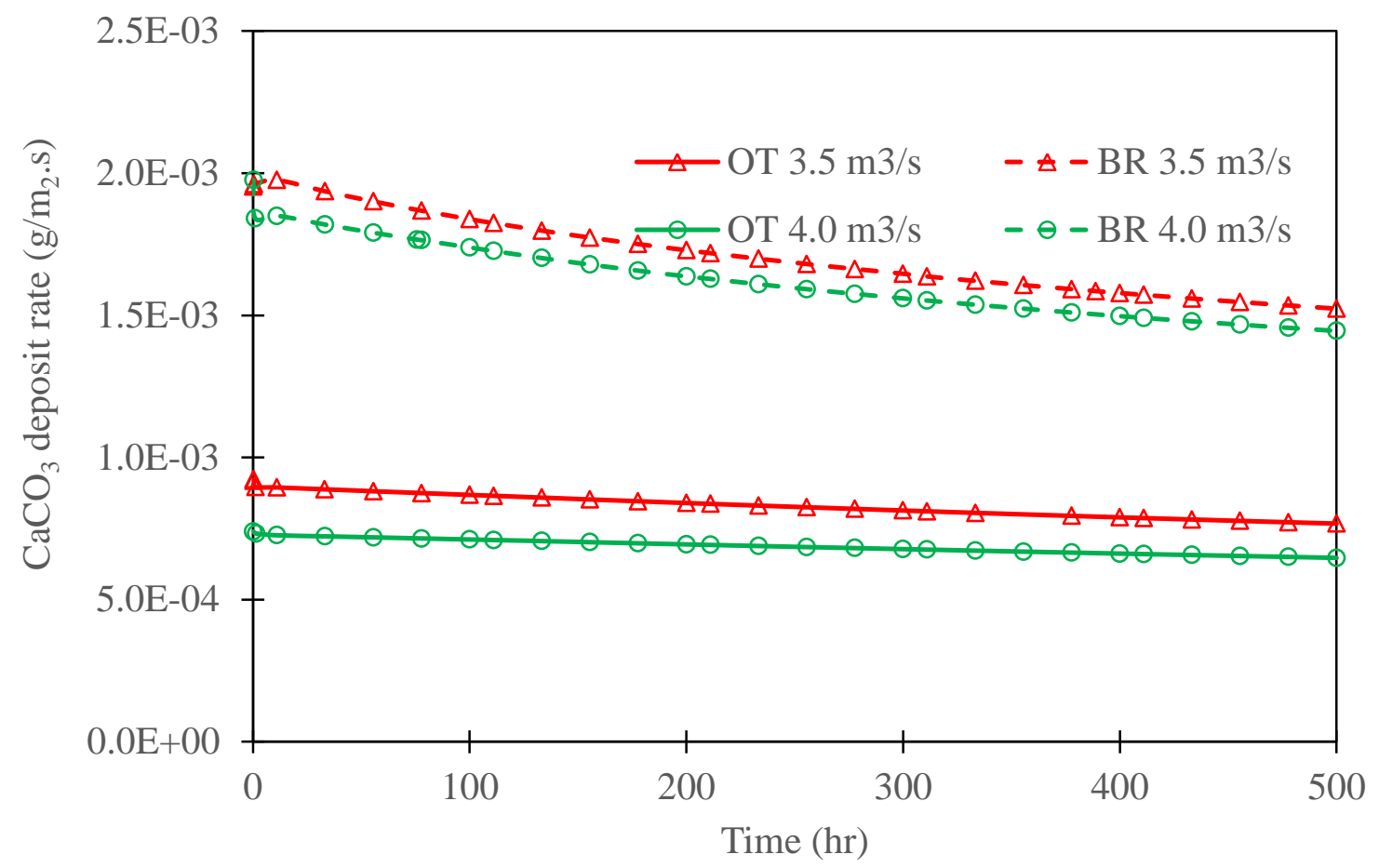

Figure 13: Velocity effect on the deposition rate of $\mathrm{CaCO}_{3}$ in the first stage in MSF-OT and MSF-BR processes.

\subsection{Effect of Seawater Salinity}

Though most of the seawater has salinity of $35 \mathrm{~g} / \mathrm{kg}(35000 \mathrm{ppm})$, this value may vary from region to region and from season to season due to the climate change. Here, in this case, the salinity of the intake seawater was varied $(35 \mathrm{~g} / \mathrm{kg}, 40 \mathrm{~g} / \mathrm{kg}$ and $45 \mathrm{~g} / \mathrm{kg}$ ) to study its effect on the fouling. It is important to mention that only the salinity was varied and other concentrations of $\left[\mathrm{Ca}^{2+}\right],\left[\mathrm{Mg}^{2+}\right],\left[\mathrm{OH}^{-}\right],\left[\mathrm{CO}_{3}{ }^{2-}\right]$, etc. were kept constant at the inlet of the plant. Figure 14 shows that crystallization of $\mathrm{CaCO}_{3}$ is slightly decreased with the increase in the seawater salinity. However, the impact of the salinity on the crystallization of calcium carbonate becomes greater at higher salinity. Hence two more values of the seawater salinity are plotted in figure 14 to observe this effect. It is to be noted such values only can be found in recycle stream in MSF-BR process but not for the intake seawater. As it can be seen from figure 14 , increasing the salinity to $55 \mathrm{~g} / \mathrm{kg}$ and further to $65 \mathrm{~g} / \mathrm{kg}$ results in remarkable decrease in the crystallization of calcium carbonate. Thus, the salinity of the intake seawater has very slight effect on the behaviour of fouling in the condenser tubes of MSF-OT process but great influence in MSF-BR process due to high salinity of the recycle stream. Figure 15, on the other hand, shows that the deposit rate of $\mathrm{Mg}(\mathrm{OH})_{2}$ noticeably increases with the increase in the seawater salinity. Though both solubility products increases with the increase in the water salinity, the $\mathrm{Mg}(\mathrm{OH})_{2}$ is less sensitive to this increase in the salinity due to the very low product solubility compared to $\mathrm{CaCO}_{3}$ and thus, it starts to precipitate more as the salinity increase. The increase in the crystallization of magnesium hydroxide despite the increase in the saturated solubility can be attributed to the increase in the $\left(\mathrm{OH}^{-}\right)$ions with the 
increase of the seawater salinity and thus with the availability of $\mathrm{OH}^{-}, \mathrm{Mg}(\mathrm{OH})_{2}$ becomes more favourable to precipitate.

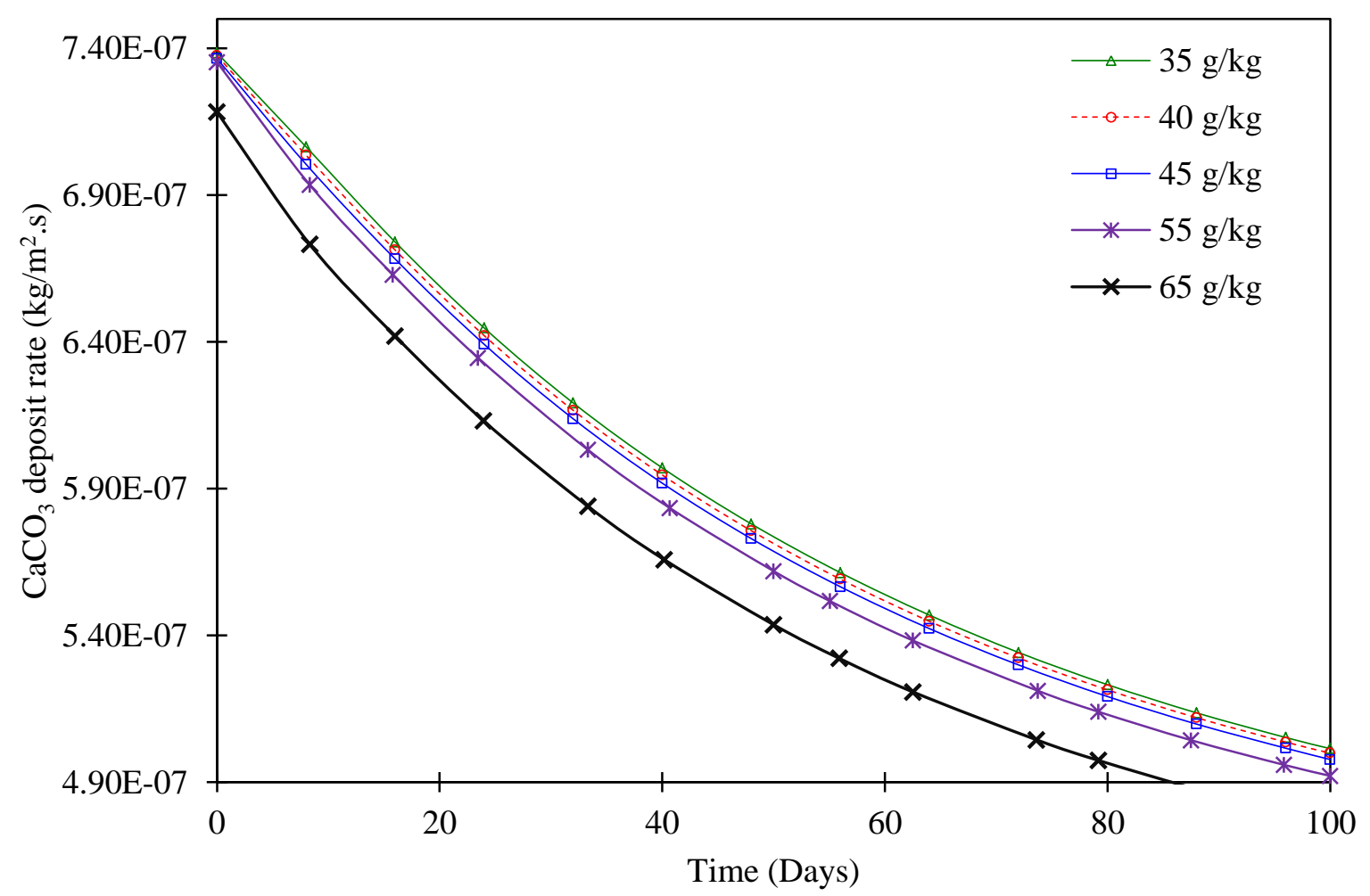

Figure 14: Salinity effect on the deposit rate of $\mathrm{CaCO}_{3}$ in the first stage.



Figure 15: Salinity effect on the deposit rate of $\mathrm{Mg}(\mathrm{OH})_{2}$ in the first stage. 


\subsection{Effect of Partial Removal of Divalent Ions from the Intake Seawater.}

In most MSF plants, the operating temperature (TBT) is limited in the range between $90{ }^{\circ} \mathrm{C}$ and $120{ }^{\circ} \mathrm{C}$. This limitation of the TBT is to avoid the likelihood of high scale crystallization at higher temperatures. Increasing the TBT and consequently the flashing range temperature has great impact on the plant performance and the water production cost. Thus, partial removal or reduction of the divalent ions such as $\mathrm{Ca}^{2+}$ and $\mathrm{Mg}^{2+}$ from the intake seawater results in low or even zero fouling and thus allow for MSF plants to operate at higher TBT. There are several suggestions in the literature to pre-treat the intake seawater by different technologies such as nanofiltration (NF) and RO. Hamed, et al. [27] studied trihybrid of $\mathrm{NF} / \mathrm{RO} / \mathrm{MSF}$ to reduce the sulphate and calcium ions in the seawater. The treated outlet from RO was used as makeup flow to the last stage of the MSF process. In their study, this integration allows the MSF process to operate safely up to TBT of $130{ }^{\circ} \mathrm{C}$. Al-Rawajfeh, et al. [28] carried out a study to predict the potential of calcium sulphate scale after using salts precipitators (SP) and NF unit as pre-treatment for MSF process. The results showed that for $50 \%$ pre-treated feed the TBT reached $145{ }^{\circ} \mathrm{C}$ and for $100 \%$ pre-treated feed, the MSF process could be operated at TBT of $175^{\circ} \mathrm{C}$.

In this section the intake seawater into the MSF process is assumed to be partially and fully treated with one of the available technology such as NF or RO. It is to note that no model or actual data is available to estimate the removal rate of the divalent ions from the seawater. However, it is assumed that the divalent ions are removed from the seawater in the range $0 \%$ to $100 \%$ in increments of $20 \%$. Figure 16 shows the increase in the performance ratio with partial removal of the divalent ions (mainly $\mathrm{Ca}^{2+}$ and $\mathrm{Mg}^{2+}$ ). This increase seems to be nonlinear with small improvement in the performance ratio at $20 \%$ removal of the divalent ions and starts to improve slowly with more reduction in the divalent ions. In addition, the results indicate that even small amount of foulants could have a large effect on the performance ratio. As it can be seen, partial removal of the foulants up to $80 \%$ does not improve the performance ratio significantly. However, removal over $80 \%$ and up to $100 \%$ of the foulants can improve the performance ratio dramatically.

It is important to point out that these results have been carried out at constant TBT of $119{ }^{\circ} \mathrm{C}$. The performance is thus expected to be improved further if the TBT is increased. The reason of not investigating the effect of TBT in this case is due to the dynamic behaviour of this model. Increasing the TBT leads to generation of more vapour and results in decrease in the brine level in the first few stages. Thus, to simulate the MSF process at higher TBT, the design configuration of the MSF plant such as the height of the gate has to be modified to control the brine level in the first few stages. 


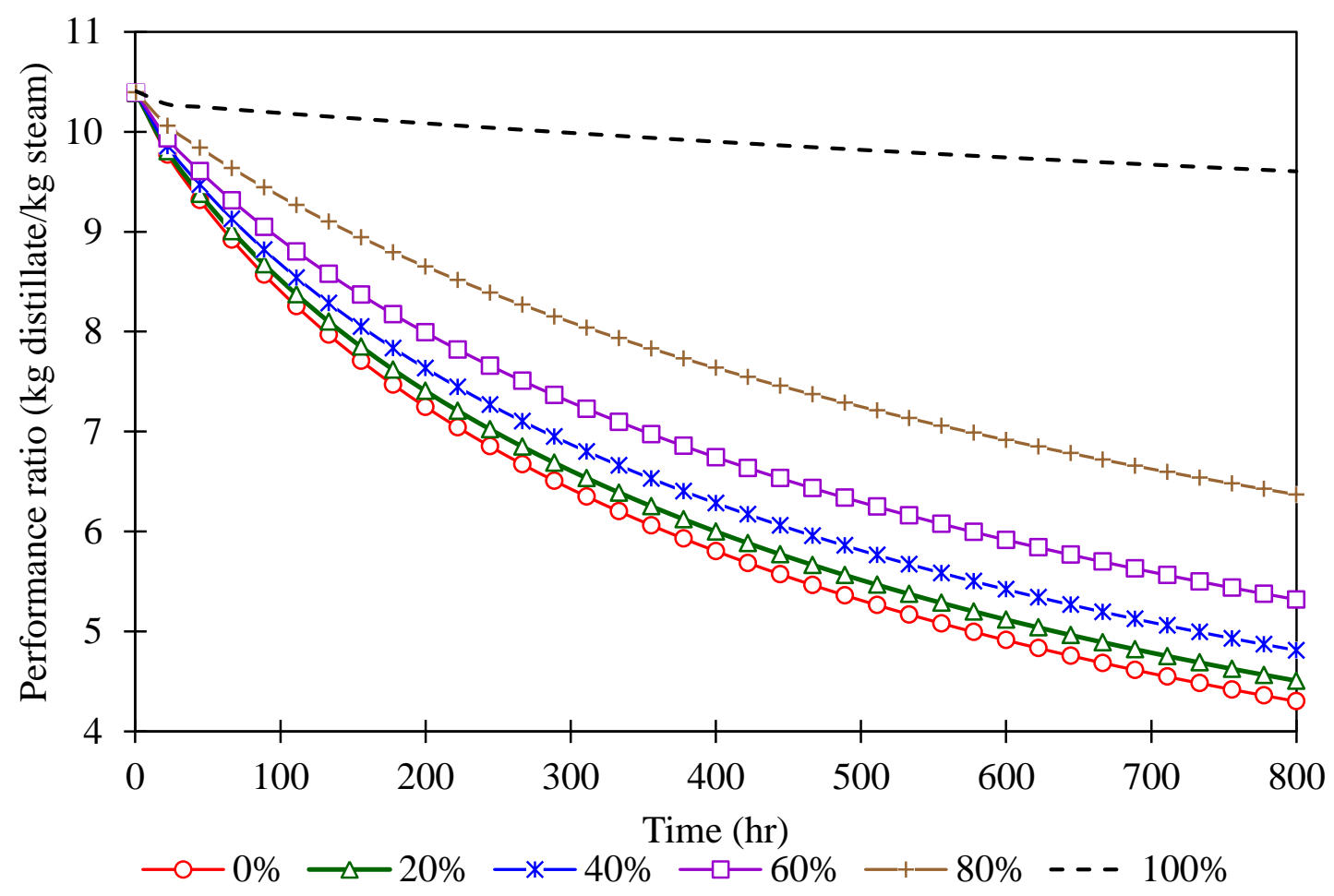

Figure 16: Effect of partial and full removal of divalent ions on the performance ratio

\section{Conclusions}

In this work, dynamic fouling model was developed to predict the rate of deposition of calcium carbonate and magnesium hydroxide in MSF-OT process. Short description of the process and the expected fouling mechanism were presented. Several parameters such as temperature (Top Brine Temperature and Seawater Temperature), flowrate and salinity were altered to investigate their effect on the scale formation in MSF-OT plant.

The outcome results indicated that the crystallization of $\mathrm{CaCO}_{3}$ and $\mathrm{Mg}(\mathrm{OH})_{2}$ strongly depend on the temperature, velocity and salinity. The results showed that the TBT has greater effect over the intake seawater temperature on the fouling process. Increasing the seawater temperature showed slight increase in the rate of fouling while increasing the TBT showed remarkable increase in fouling. In addition, at lower TBT, the rate of deposition of $\mathrm{CaCO}_{3}$ was higher compared to the rate of deposition of $\operatorname{Mg}(\mathrm{OH})_{2}$. However, at higher $\mathrm{TBT}\left(120{ }^{\circ} \mathrm{C}\right)$ the concentration of fouling of $\mathrm{CaCO}_{3}$ and $\mathrm{Mg}(\mathrm{OH})_{2}$ were varied over the stages. The results showed that the crystallisation of $\mathrm{CaCO}_{3}$ was found in high concentration in the middle stage while in the first few stages, the crystallisation of $\mathrm{Mg}(\mathrm{OH})_{2}$ was higher.

The solubility of the $\mathrm{CaCO}_{3}$ and $\mathrm{Mg}(\mathrm{OH})_{2}$ decreases with increasing temperature resulting in crystallization of the fouling species. On the contrary, the solubility of $\mathrm{CaCO}_{3}$ and $\mathrm{Mg}(\mathrm{OH})_{2}$ increases with increasing salinity leading to lower crystallization of $\mathrm{CaCO}_{3}$. Though high tendency of fouling is expected in brine recycle MSF process (MSF-BR) [12], this due to high concentration of seawater species in the recycle stream and not because of high salinity. In the presence of $\mathrm{Mg}$ and $\mathrm{Ca}$, the priority of crystallization depends on the $\mathrm{Ca} / \mathrm{Mg}$ or $\mathrm{CO}_{3} / \mathrm{OH}$ ratio. Though both concentration of $\left[\mathrm{CO}_{3}{ }^{2-}\right]$ and $\left[\mathrm{OH}^{-}\right]$ increase with the increase in the salinity, the ratio $\mathrm{CO}_{3} / \mathrm{OH}$ decreases leading to crystallisation of $\mathrm{Mg}(\mathrm{OH})_{2}$ becoming more favourable. Moreover, increasing the flow 
velocity results in the reduction of the residence time of the fluid inside the tubes surface and consequently decrease the probability of the fouling to occur. Note with time, though the thickness of the fouling layer increases, the fouling rate decreases due to the drop in the surface temperature.

Finally, the results showed that the partial or full removal of the divalent ions such as $\mathrm{Ca}^{2+}$ and $\mathrm{Mg}^{2+}$ from the intake seawater by one of the available technology such as NF or RO can allow MSF plants to operate at higher temperature and thus improve the performance ratio of the plants.

\section{Nomenclature}

Debye-Huckel constant

$a_{i}$

Debye-Huckel parameter (ion specific parameter)

$B$

Debye-Huckel parameter (temperature dependent parameter)

$b_{i}$

Debye-Huckel parameter (ion specific parameter)

$C_{b}$

Concentration of ions in the fluid $\left(\mathrm{kg} / \mathrm{m}^{3}\right)$

$C_{s}$

Saturation concentration $\left(\mathrm{kg} / \mathrm{m}^{3}\right)$

d

Tube diameter $(\mathrm{m})$

$E_{a}$

Reaction activation energy (kJ/mole)

$g$

Gravitational acceleration $\left(\mathrm{m} / \mathrm{s}^{2}\right)$

$h$

Heat transfer coefficient $\left(\mathrm{kW} / \mathrm{m}^{2 \mathrm{o}} . \mathrm{K}\right)$

Ionic strength $(\mathrm{mol} / \mathrm{kg})$

$i$

Inner

$k_{r}$

Reaction rate constant $\left(\mathrm{m}^{4} / \mathrm{s}^{2} . \mathrm{kg}\right)$

$k_{\text {rem }}$

Removal rate constant $\left(\mathrm{m}^{3} / \mathrm{s} . \mathrm{kg}\right)$

$K_{r 0}$

Pre-exponential constant $\left(\mathrm{m}^{4} / \mathrm{s}^{2} \cdot \mathrm{kg}\right)$

$k_{s p}$

Solubility product $\left(\mathrm{mole}^{2} / \mathrm{kg}^{2}\right)$

$k_{s p}^{0}$

Solubility product constant $\left(\right.$ mole $\left.{ }^{2} / \mathrm{kg}^{2}\right)$

$k_{t}$

Conductivity of the tube material $\left(\mathrm{kW} / \mathrm{m}^{\mathrm{o}} . \mathrm{K}\right)$

$K_{w}$

Dissociation constant for water (mole/kg)

$K_{1}$

First dissociation constant (mole/kg)

$K_{2}$

Second dissociation constant (mole/kg)

$m_{d} \quad$ Deposit mass rate $\left(\mathrm{kg} / \mathrm{s} . \mathrm{m}^{2}\right)$

$m_{f}$

Net deposit mass rate $\left(\mathrm{kg} / \mathrm{s} . \mathrm{m}^{2}\right)$

$m_{i} \quad$ Molality of ion i

$m_{r} \quad$ Removal mass rate $\left(\mathrm{kg} / \mathrm{s} . \mathrm{m}^{2}\right)$

$o \quad$ Outer

$R_{f} \quad$ Fouling resistance $\left(\mathrm{m}^{2}{ }^{\circ} . \mathrm{K} / \mathrm{kW}\right)$ 
TA Total alkaline (mole $/ \mathrm{kg})$

TC Total carbon dioxide (mole $/ \mathrm{kg})$

$T_{s} \quad$ Surface temperature $\left({ }^{\circ} \mathrm{C}\right)$

$U_{0} \quad$ Overall heat transfer coefficient $\left(\mathrm{kW} / \mathrm{m}^{20} \mathrm{C}\right)$

$V \quad$ Friction velocity $(\mathrm{m} / \mathrm{s})$

$z_{i} \quad$ Charge of the ion $i$

\section{Greek letters}

$\beta$

Mass transfer coefficient $(\mathrm{m} / \mathrm{s})$

$\gamma$

Activity coefficients.

if Conductivity of the fouling layer $(\mathrm{kW} / \mathrm{m} . \mathrm{K})$

$\mu_{w} \quad$ Viscosity of the fluid (N.s $/ \mathrm{m}^{2}$ )

$\rho_{f} \quad$ Density of the fouling layer $\left(\mathrm{kg} / \mathrm{m}^{3}\right)$

$\rho_{w} \quad$ Density of the fluid $\left(\mathrm{kg} / \mathrm{m}^{3}\right)$

$\sigma_{f} \quad$ Shear strength of the fouling layer $\left(\mathrm{N} / \mathrm{m}^{2}\right)$

$\tau_{f} \quad$ Surface shear stress of the bulk flow $\left(\mathrm{N} / \mathrm{m}^{2}\right)$

\section{References}

[1] H. Baig, M. A. Antar, and S. M. Zubair, "Performance evaluation of a once-through multistage flash distillation system: Impact of brine heater fouling," Energy Conversion and Management, vol. 52, pp. 1414-1425, 2011.

[2] A. Husain, K. Wangnick, and A. Radif, "Case Study on Planning a Large Scale Multistage Flash Desalination Plant," Thermal Desalination Processes. Eolss Publishers, Oxford, UK, Encyclopedia of Desalination and Water Resources, 2004.

[3] A. M. Shams El Din and R. A. Mohammed, "Brine and scale chemistry in MSF distillers," Desalination, vol. 99, pp. 73-111, 1994.

[4] S. N. Kazi, Fouling and fouling mitigation on heat exchanger surfaces: INTECH Open Access Publisher, 2012.

[5] K. Al-Anezi and N. Hilal, "Scale formation in desalination plants: effect of carbon dioxide solubility," Desalination, vol. 204, pp. 385-402, 2007.

[6] E. A. M. Hawaidi and I. M. Mujtaba, "Simulation and optimization of MSF desalination process for fixed freshwater demand: Impact of brine heater fouling," Chemical Engineering Journal, vol. 165, pp. 545-553, 2010/12/01/ 2010.

[7] A. Mubarak, "A kinetic model for scale formation in MSF desalination plants. Effect of antiscalants," Desalination, vol. 120, pp. 33-39, 1998.

[8] A. E. Al-Rawajfeh, M. Al-Garalleh, G. Al-Mazaideh, B. a. Al-Rawashdeh, and S. Khalil, "Understanding $\mathrm{CaCO}-\mathrm{Mg}(\mathrm{OH}) 2$ scale formation: a semi-empirical mindo-forces study of CO2-H2O system," Chemical Engineering Communications, vol. 195, pp. 998-1010, 2008.

[9] A. E. Al-Rawajfeh, S. Ihm, H. Varshney, and A. N. Mabrouk, "Scale formation model for high top brine temperature multi-stage flash (MSF) desalination plants," Desalination, vol. 350, pp. 53-60, 2014. 
[10] S. M. Alsadaie and I. M. Mujtaba, "Dynamic modelling of Heat Exchanger fouling in multistage flash (MSF) desalination," Desalination, vol. 409, pp. 47-65, 5/1/ 2017.

[11] S. Said, I. M. Mujtaba, and M. Emtir, "Effect of Fouling Factors on the Optimisation of MSF Desalination Process for Fixed Water Demand Using gPROMS," in Proceeding of the 9th International Conference on Computational Management, London, UK, 2012.

[12] H. El-Dessouky, I. Alatiqi, and H. Ettouney, "Process synthesis: the multi-stage flash desalination system," Desalination, vol. 115, pp. 155-179, 1998.

[13] A. M. S. El Din, M. E. El-Dahshan, and R. A. Mohammed, "Inhibition of the thermal decomposition of HCO 3- A novel approach to the problem of alkaline scale formation in seawater desalination plants," Desalination, vol. 142, pp. 151-159, 2002.

[14] R. Segev, D. Hasson, and R. Semiat, "Rigorous modeling of the kinetics of calcium carbonate deposit formation," AlChE Journal, vol. 58, pp. 1222-1229, 2012.

[15] M. Ø. Olderøy, M. Xie, B. L. Strand, E. M. Flaten, P. Sikorski, and J.-P. Andreassen, "Growth and nucleation of calcium carbonate vaterite crystals in presence of alginate," Crystal Growth \& Design, vol. 9, pp. 5176-5183, 2009.

[16] S. Patel and M. A. Finan, "New antifoulants for deposit control in MSF and MED plants," Desalination, vol. 124, pp. 63-74, 1999.

[17] V. N. Slesarenko, V. G. Dobrzansky, and V. V. Slesarenko, "The account of heat exchange features when modelling scale formation at distillation plants," Desalination, vol. 152, pp. 229-236, 2003.

[18] S. M. Alsadaie and I. M. Mujtaba, "Modelling and Simulation of MSF Desalination Plant: The Effect of Venting System Design for Non-Condensable Gases," CHEMICAL ENGINEERING, vol. 39, 2014.

[19] T. M. Pääkkönen, M. Riihimäki, C. J. Simonson, E. Muurinen, and R. L. Keiski, "Modeling CaCO 3 crystallization fouling on a heat exchanger surface-Definition of fouling layer properties and model parameters," International Journal of Heat and Mass Transfer, vol. 83, pp. 84-98, 2015.

[20] F. Brahim, W. Augustin, and M. Bohnet, "Numerical simulation of the fouling on structured heat transfer surfaces (fouling)," 2003.

[21] F. Brahim, W. Augustin, and M. Bohnet, "Numerical simulation of the fouling process," International Journal of Thermal Sciences, vol. 42, pp. 323-334, 2003/03/01/ 2003.

[22] S. M. Alsadaie and I. M. Mujtaba, "Generic Model Control (GMC) in Multistage Flash (MSF) Desalination," Journal of Process Control, vol. 44, pp. 92-105, 2016/08/01/ 2016.

[23] S. F. Mussati, P. A. Aguirre, and N. J. Scenna, "Improving the efficiency of the MSF once through (MSF-OT) and MSF-mixer (MSF-M) evaporators," Desalination, vol. 166, pp. 141-151, 2004.

[24] R. Dooly and J. Glater, "Alkaline scale formation in boiling sea water brines," Desalination, vol. 11, pp. 1-16, 1972/08/01/ 1972.

[25] A. Helalizadeh, H. Müller-Steinhagen, and M. Jamialahmadi, "Mixed salt crystallisation fouling," Chemical Engineering and Processing: Process Intensification, vol. 39, pp. 29-43, 2000.

[26] F. Fahiminia, A. P. Watkinson, and N. Epstein, "Early events in the precipitation fouling of calcium sulphate dihydrate under sensible heating conditions," The Canadian Journal of Chemical Engineering, vol. 85, pp. 679-691, 2007.

[27] O. A. Hamed, A. M. Hassan, K. Al-Shail, and M. A. Farooque, "Performance analysis of a trihybrid NF/RO/MSF desalination plant," Desalination and Water Treatment, vol. 1, pp. 215222, 2009.

[28] A. E. Al-Rawajfeh, H. E. S. Fath, and A. A. Mabrouk, "Integrated salts precipitation and nanofiltration as pretreatment of multistage flash desalination system," Heat Transfer Engineering, vol. 33, pp. 272-279, 2012. 
